\title{
NUEVAS INFRAESTRUCTURAS URBANAS AL SERVI- CIO DEL TRANSPORTE Y LA LOGÍSTICA EN VALLADO- LID: LA PROGRESIVA CONSOLIDACIÓN ESPACIAL DE UN NUEVO MODELO DE ACTIVIDAD ${ }^{\prime}$
}

\author{
Basilio CALDERÓN CALDERÓN \\ Departamento de Geografía. Universidad de Valladolid
}

Recibido: 11/10/2013

Aceptado: 19/12/2013

RESUMEN: Las ciudades españolas han tenido que hacer frente en las últimas décadas a un conjunto creciente de problemas ocasionados por el tráfico y estacionamiento de vehículos pesados, así como por las operaciones de carácter logístico asociadas al transporte de mercancías. Desde 2005, la solución a esta situación en Castilla y León, ha consistido en el diseño de una red de infraestructuras públicas de altas prestaciones -denominada CyLOG-, de ubicación esencialmente urbana, para ofrecer servicios logísticos de calidad a las empresas. El Centro Integrado de Mercancías de Valladolid -CENTROLID-, operativo desde 1997, es uno de los que se integran en la misma, constituyendo una singular y atractiva práctica de ordenación de las actividades logísticas en las ciudades españolas, aunque limitada por su carácter monomodal y por su reducido tamaño, prácticamente ya agotado al finalizar el año 2013.

PALABRAS CLAVE Transporte, actividades logísticas, Castilla y León, Valladolid.

NEW URBAN INFRASTRUCTURES SER VING TRANSPORT AND LOGISTICS IN VALLADOLID: PROGRESSIVE SPATIAL CONSOLIDATION OF A NEW MODEL OF ACTIVITY

ABSTRACT: In recent decades Spanish cities have been forced to tackle a growing series of problems caused by heavy vehicle traffic and parking, as well as logistic operations associated with goods transport. Since 2005, the solution to these problems in Castilla y León has been based on the design of a high performance infrastructures network - known as the CyLOG. Centred mainly in urban locations, the aim is to offer quality logistic services to companies. CENTROLID, - Valladolid's Integrated Goods Centre - which has been operational since 1997, is one such infrastructure, constituting an outstanding and attractive means of organising logistic activity in

1 El presente texto se incardina en el proyecto de investigación Las ciudades españolas en la etapa autonómica (1978-2012). Dinámicas, procesos y políticas (URBSPAIN), financiado por el Plan Nacional de Investigación I+D+i del Ministerio de Economía y Competitividad para el período 2010-2013 (Código CSO 2009-11261-Subpr. GEOG). 
Spanish cities, despite the limitations caused by its mono-modal and ephemeral character and its reduced size in terms of capacity, which by 2014 will be practically exhausted.

KEY WORDS Transport, logistics, Castilla y León Community, Valladolid

\section{INTRODUCCIÓN: EL IMPACTO ESPACIAL DE LA ACTIVIDAD LOGÍSTICA}

En las últimas décadas se viene asistiendo a un notable incremento del transporte de mercancías por carretera en España, y que este hecho ha dado lugar a que un considerable número de ciudades haya tenido que afrontar los crecientes y acuciantes problemas ocasionados por el tráfico y estacionamiento de pesados, así como por las operaciones asociadas al transporte de mercancías que se realizan en empresas ubicadas en el interior de las ciudades sea o no este su mercado potencial o natural (RoBUSTÉ, 1999). Para resolver en parte esta situación y como respuesta a las necesidades del transporte y de ordenación-zonificación de la ciudad, han ido surgiendo en la práctica totalidad de las regiones españolas diversas infraestructuras de apoyo al transporte de mercancías, en la práctica un nuevo tipo de equipamiento, habitualmente de escala metropolitana, esencial para garantizar la competitividad de la economía local y global de un país; unas infraestructuras de tamaño, complejidad interna, servicios asociados y denominación diversa, ya sean centros integrados de mercancías, centros de transporte, centros de distribución de mercancías, plataformas logísticas, parques logísticos, áreas de actividades logísticas, zonas de actividades logísticas, ciudades del transporte u otras de naturaleza similar, jerarquizadas mediante la combinación de dos criterios básicos: el tamaño y la tipología de los servicios ofrecidos al transporte y a la cadena logística, considerando que los rasgos básicos de la urbanización de estos espacios, tales como playas de maniobras, tamaño y jerarquía de los viales y accesos son similares en todos los casos.

En consonancia con este creciente interés y con el despliegue de infraestructuras logísticas, el avance de la Estrategia Logística de España, publicado el 8 de Julio de 2013, considera que esta actividad está llamada a desempeñar un papel de creciente importancia en el sistema productivo, ya que, una logística eficiente constituye un factor clave para impulsar la competitividad. ${ }^{2} \mathrm{Y}$ es que se trata de una actividad que se ocupa de todos los medios, métodos y actividades que intervienen en la cadena de aprovisionamiento y distribución y que comprende el diseño, implementación y control del flujo de materias primas, el

$2 \mathrm{http}: / / \mathrm{www} . c a d e n a d e s u m i n i s t r o . e s / \mathrm{wp}$-content/uploads/2013/07/Avance Estrategia_Logistica.pdf 
inventario del proceso, los productos terminados y la información relacionada, siendo su objetivo final asegurar la eficiencia de este conjunto de procesos desde el punto de origen de un producto hasta el punto de su consumo. Es comprensible por ello que en los últimos años se haya venido prestando por parte de las administraciones regionales y municipales una atención creciente a todos los aspectos convencionalmente agrupados bajo el concepto de logística, por entender que se trata del ámbito en el que confluyen intereses y estrategias diversas, tanto de las actividades de producción (GUTIERREZ y GARCIA, 2010: 381) como de transporte y consumo, y por considerar que "las actividades relacionadas con la moderna logística son un nicho económico emerente, protagonista de nuevos procesos económicos y espaciales" (DEL Rio y RodRIGUEZ , 2012: 277). Este interés se ha traducido, obviamente, en una multiplicación de estudios, normas e instrumentos o entidades de gestión relacionados con la logística, contemplada ésta en unos casos como estrategia de organización, en otros casos como actividad vinculada al transporte, e incluso y no por ello menos relevante, como estrategia política de vertebración regional; no sorprende por ello que gran parte de las Comunidades Autónomas hayan elaborado normativas y planes propios, con los que regular las áreas o centros de transporte de mercancías, destacando los casos de (Castilla y León -Red de enclaves logísticos CYLOG-, Castilla La Mancha -Plan Estratégico de Plataformas Logísticas-, Madrid -Plan de Infraestructuras de la Comunidad de Madrid-, País Vasco -Plan Territorial Sectorial de la Red Intermodal y Logística del Transporte en la Comunidad Autónoma del País Vasco--, por señalar tan solo alguno de los más completos y representativos (MINISTERIO DE FOMENTO, 2013: 39) .

Como resultado de todo ello, el desarrollo de las grandes áreas logísticas -zonas de actividades logísticas- ha sido espectacular; junto a las de carácter portuario como las de Barcelona -200 ha.- (Oliveras,2009: 27), Sevilla -36 haValencia -68 ha-, Vigo, Gijón, Motril -40 ha-, Bilbao -34 ha-, en los últimos años se ha asistido a la creación en el interior peninsular de múltiples centros logísticos de escala y soporte institucional diverso, que por lo general responden o bien a la proximidad de grandes centros de actividad, o se ubican en alguno de los grandes nodos de transporte, o bien operan como Puertos Secos para el despliegue de la actividad logística de alguno de los grandes puertos españoles ${ }^{3}$. Con relación a los primeros, algunos autores (Morales, 2010: 220; Del Rio y Rodriguez, 2012: 286) destacan los casos de Madrid: Centro de Transportes de Coslada, el Puer-

3 En distintas fases de proyecto o ejecución se encontraban en 2013 las Zonas de Actividades Logísticas -ZAL- de Salvaterra-As Neves -Vigo-, con 419 ha., Algeciras, Gijón ZALIA-, 313 has., Ferrol, 44 ha., Parc Castelló, 200 ha., Sagunto, 30 ha., Cartagena, Santander, Tarragona, 104 ha., Alicante, 12, ha., o Las Palmas, 30 ha. 
to Seco, el Centro de Carga Aérea de Barajas, el Centro Logístico Intermodal del Este, la Estación de Contenedores de Vicálvaro, el centro Logístico Meco, el polígono de Garena de Alcalá de Henares, Mercamadrid, RENFE Abroñigal, Carpetiana; es también relevante el caso de Barcelona: el Centro de Carga Aérea, Mas Blau, ProLogis San Bou de Llobregat, el Parque Logístico de la Zona Franca, la Central Integrada de Mercancías de Vallés. ${ }^{4}$ En situación equivalente, en su escala, se encuentra la ciudad de Sevilla, Valencia, Gijón o Bilbao ciudad que, dada la congestión de la Ría de Nervión, ha impulsado la pequeña Plataforma de Vitoria -Arasur-. Por otra parte, además de los señalados, resulta oportuno destacar el papel de los grandes Puertos Secos: Coslada, Azuqueca de Henares, TMZ de Zaragoza, o Gijón, -Ventastur- (Fernandez, 2013:60; RodríGuez, 2010: 390) ubicado en la localidad palentina de Venta de Baños, en competencia directa con el Enclave Central de la red logística de Castilla y León, CyLOG, (LóPEz, BENIto, 2012) que, todavía en fase de construcción en 2013, está llamado a ser el mayor centro logístico no urbano-no portuario de España, en una proporción similar a PLAZA, la gran plataforma logística de Aragón.

La ubicación de este amplio y creciente conjunto de Puertos Secos y sobre todo la que algún autor denomina áreas logísticas intermedias (Morales, 2010: 213), precisa de algunos requisitos singulares, y especialmente dos: por una parte la existencia de un nodo geoestratégico de los transportes terrestres que vinculen las grandes ZAL portuarias con las grandes aglomeraciones urbanas y por otra, la existencia de polígonos industriales a los que servir, donde los transportes terrestres rápidos -ferrocarril o autopista- se encarguen de cumplir con las exigencias de los actuales intercambios comerciales, ya sea a escala regional, nacional o internacional; estas áreas logísticas intermedias son de carácter esencialmente urbano, tienen un alcance limitado ya que habitualmente están apoyadas en un solo modo, la carretera. Pese a ello, la atención que se ha prestado al análisis del impacto espacial, en la escala local, de las mismas es relativamente modesto, a pesar de que, su emergente presencia en la ciudad española se ha resuelto en la realización de un amplio conjunto de buenas prácticas relacionadas con su ubicación y diseño urbano. Y es que, como señalan alguno autores (RoBusté, 1999) "El transporte de mercancías por carretera en España, y en mayor o menor medida en el conjunto de Europa, implica que un notable número de ciudades deba afrontar los crecientes y acuciantes problemas ocasionados por el tráfico y estacionamiento de pesados, así como por las operaciones asociadas al transporte de mercancias que se realizan en empresas ubicadas en el interior de las ciudades".

$4 \quad$ http://blocs.gencat.cat/blocs/AppPHP/ptop/files/2010/05/especial-vigia-17052010.pdf http://www.barcelona-plataformalogistica.com/ 
En consonancia con ello, la presente investigación tiene por objeto analizar los atributos objetivos que justifican la creación en la década de los años noventa del siglo XX de un centro de transporte o una zona de actividades logísticas en Valladolid, que ordenase esta actividad dispersa por la ciudad, relacionados con la densidad y capacidad de las infraestructuras de transporte y de suelo industrial; verificados ambos se realiza un estudio de tal proceso, comenzando por la génesis del primitivo Centro Integrado de Mercancías, la relativa idoneidad de su emplazamiento, que anula parcialmente los efectos de lo que en origen era una buena práctica urbana, y una adecuada solución urbanística, así como su incorporación a la red CyLOG hasta completar la ocupación de las modestas 18 has. previstas. Finalmente, se hace un somero análisis de las alternativas al agotamiento del modelo, vinculadas, ahora sí, a la mejora de la modalidad que permite la proximidad a las nuevas infraestructuras viarias y ferroviarias que serán inauguradas en los primeros meses del año 2014: la Ronda Exterior -Va-30- y el nuevo complejo ferroviario -bypass- del este en el que se ha construido ya el Taller Central de Reparaciones - TCR- y una extensa terminal de mercancías y área logística anexa.

Desde el punto de vista metodológico el estudio atribuye un papel esencial en el desarrollo de esta nueva actividad urbana a la estructura de la red de transporte, razón por la cual se dedica un capítulo importante a verificar su estado y previsiones de desarrollo en el futuro; asegurada esta infraestructura el estudio aborda el proceso de delimitación del primitivo centro logístico a partir de los condicionantes del planeamiento urbanístico; con tal objeto se ha hecho un exhaustivo análisis de la muy prolija documentación generada a lo largo del proceso tanto de ordenación como de gestión, -ver anexo 3- al objeto de comprobar la coherencia formal y temporal de sus propuestas; en el mismo sentido, se ha elaborado una matriz de datos conteniendo toda la información aportada por los agentes y operadores en las dos últimas décadas, clasificada por materias, carácter de la misma y momento en el que se genera, al objeto de comprobar la idoneidad y en su caso deficiencias que presenta la actual ubicación del centro integrado de mercancías y sus posibles y necesarias alternativas a la vista del agotamiento del espacio y modelo de actividad. Finalmente se ha analizado, de forma pormenorizada, la que está llamada a ser alternativa logística completa y coherente, a partir de la documentación, en fase de tramitación y aprobación, del plan parcial de los sectores 48 y 49 del PGOU de Valladolid en vigor en 2013: Arenal y Vereda de Palomares. 


\section{DOS FACTORES PARA IMPULSAR EL CENTRO INTEGRADO DE MERCANCÍAS DE VALLADOLID: UNA SITUACIÓN ESTRA- TÉGICA EN LA RED DE TRANSPORTE Y UNA DENSA TRAMA DE ÁREAS INDUSTRIALES}

En las Directrices Esenciales de Ordenación del Territorio de Castilla y León, aprobadas por ley $3 / 2008$, de 17 de junio, y en consonancia con los principios generales de desarrollo sostenible y equilibrio territorial, se proponen diversos objetivos de entre los que destacan los relacionados con la modernización de las infraestructuras de transporte y la necesidad de completar el «mapa logístico» regional. En el desarrollo de esta estrategia, la posición de la provincia de Valladolid y singularmente de su capital es muy relevante, reforzada además por el hecho de que, en una de las vías de alta capacidad que vertebra la Región, la Autovía de Castilla, A-62 /E.80, se localiza uno de los ámbitos más dinámicos de Castilla y León, el corredor Valladolid-Palencia-Burgos, que puede considerarse como el espacio medular de la industria regional, ya que operan en él gran parte de las mayores firmas industriales implantadas en la misma (CALDERón y PASCUAL, 2009: 239), así como una densa red de pequeñas y medianas empresas, cuya capacidad de generación de trabajo industrial alcanza aquí las cifras más elevadas, ya que, en algo más de 1.800 establecimientos industriales, se concentran en él cerca de 50.000 empleos (PASCUAL, 2012: 672). A mayor abundamiento, en el proceso de construcción de la red de alta velocidad, la localidad de Venta de Baños, en la que se está construyendo el Enclave Central de la red de Enclaves Logísticos de Castilla y León-CyLOG-, pasa a ser el nudo -entendido como el punto en que se unen varias vías de comunicación-, del triángulo ferroviario que conectará la línea Valladolid-Palencia-León-Asturias, con la de Venta de Baños-Burgos Vitoria- Frontera Francesa, de tal manera que será posible llevar a cabo todos los movimientos directos posibles entre las ciudades de Valladolid, Palencia y Burgos, reforzando el carácter estratégico de la actividad logística en los cuatro puntos, y especialmente en Valladolid. ${ }^{5}$

\section{II.1 Valladolid ciudad encrucijada: los corredores viarios de conexión internacional - Autovía de Castilla E-80/A-62, y del Duero E-82/A-11 y las autovías A-601 -Valladolid-Segovia- y A-60 -Valladolid-León-.}

Al margen de las consideraciones históricas o de la situación geográfica, es obvio que, en la actualidad, el alto grado de accesibilidad y centralidad de la ciu-

5 http://www.adif.es/ 
dad de Valladolid se debe, fundamentalmente, al trazado, capacidad y previsiones de transformación asociada a su condición de encrucijada viaria para el trafico peninsular, ya que en ella se articula el tráfico de la A-62, con el proveniente de la Autovía de Pinares, la A-601, y con el que canalice la autovía de León, A-60, y la autovía del Duero, A-11, ambas en construcción en el año 2014; una situación en cierto modo privilegiada en los momentos actuales, dado el carácter dominante del transporte de mercancías por carretera en España, ya que supone más el $85 \%$ de las toneladas-km transportadas (85,3\% en 2011), mientras, que el transporte marítimo representa un 12,2\% y el ferroviario sólo alcanza el 2,5\% (MINISTERIO DE FOMENTO, 2013: 206). Ello no obstante, y como sucede con cualquier infraestructura viaria, lo verdareramente relevante no es su trazado, sino los territorios cercanos y lejanos que comunica, y la capacidad para obtener en un punto dado, las sinergias derivadas del tránsito de mercancías que soporta, poniendo en valor las áreas de actividad ya existentes, especialmente las de la capital provincial, o alentando el desarrollo de otras nuevas como las de Venta de Baños-Villamuriel-Magaz y Tordesillas, por señalar los dos extremos estratégicos del corredor de actividad de la A-62.

En efecto, la Autovía de Castilla E-80/A-62 es un destacado eje integrante de las Redes Transeuropeas de Transporte, que propicia la conexión de dos importantes regiones del Arco Atlántico: la denominada "Rótula" del País Vasco (confluencia del corredor Madrid-París, del eje del Ebro y del eje de la Fachada Cantábrica) con el corredor atlántico portugués Lisboa-Oporto. La Autovía de Castilla-N-620-IP-5, en definitiva, el Itinerario Europeo E-80, constituye la principal ruta de comunicación entre Portugal y el resto de la Unión Europea, perfilándose, asimismo, como el más importante segmento de enlace de la Región Norte portuguesa con Castilla y León. Se localiza en él, con centro de gravedad en la ciudad de Valladolid, el tramo de actividad más dinámico del mismo: el extendido entre Venta de Baños y Tordesillas, municipios en los que, y no por casualidad, se han emplazado dos infraestructras de alto valor estratégico: el Area Central de la red CyLOG y el puerto seco de Gijón- Ventastur- en el primer caso, y un polígono industrial logístico promovido por SEPES -no integrado aún en la red CyLOG- en el segundo, para aprovechar el enorme potencial del encuentro de los grandes ejes viarios de conexión norte-sur, la A-6, autovía del Noroeste, y este oeste, la A-62 autovía de Castilla-. A mayor abundamiento, la Autovía de Castilla A-62, propicia el enlace de este dinámico corredor con otros dos centros urbanos regionales de entidad, Burgos y Salamanca, actuando como soporte en la articulación interna del más dinámico eje de desarrollo castellano-leonés, la denominada Diagonal Castellana, (CAlderón, Pascual y Pastor, 2005:155). 
Figura 1: Grandes ejes estructurantes -alta capacidad- en la provincia de Valladolid (Red estatal y autonómica, horizonte 2020).

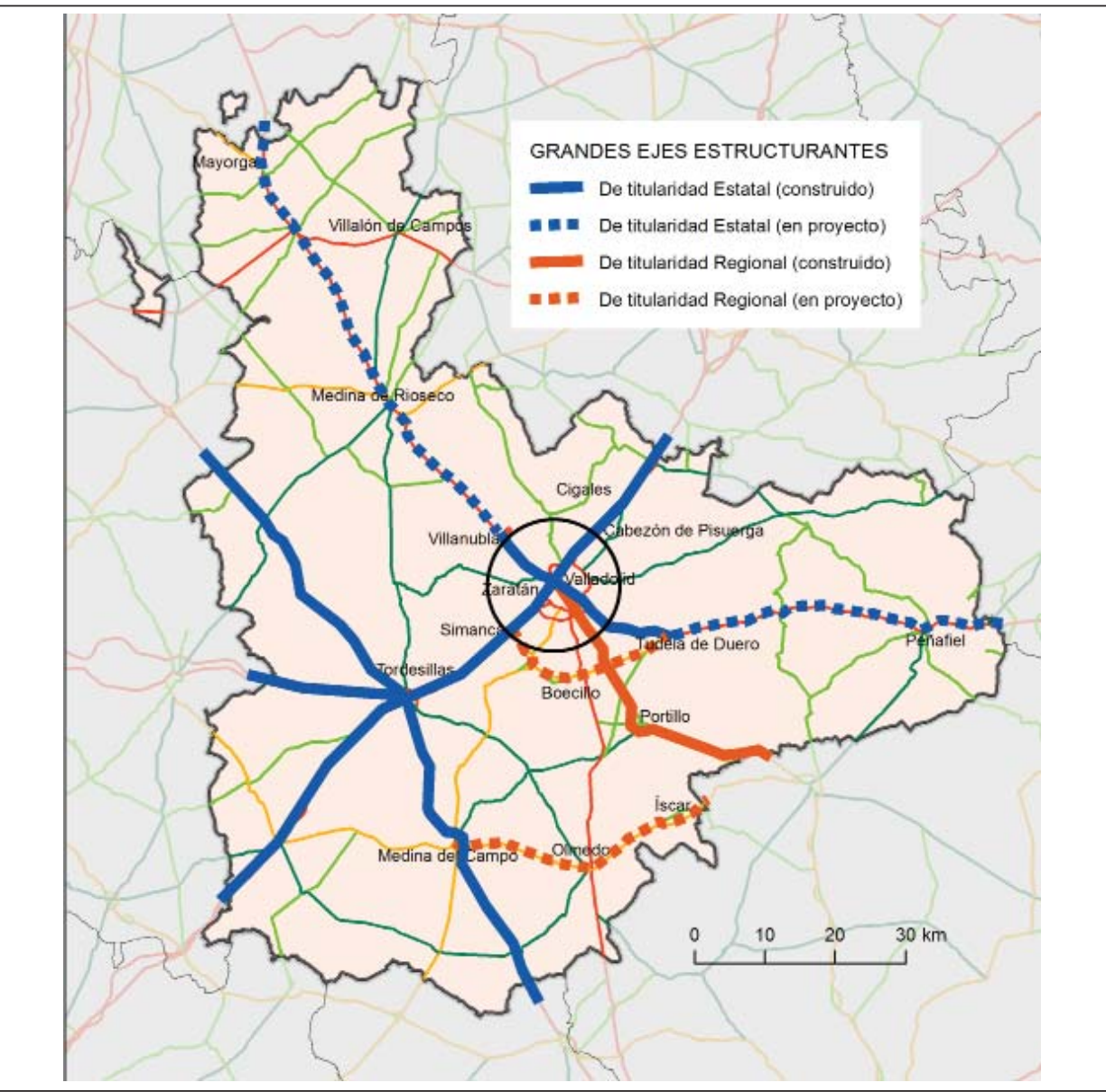

FUENTE: JCyL: Plan sectorial regional de carreteras 2008-2020 y elaboración propia

Dos grandes proyectos han venido a reforzar, en la primera década del siglo XXI, el carácter de este eje: en primer lugar la construcción en la provincia de Valladolid del Área de Actividades Canal de Castilla, un macropolígono de 353 hectáreas de superficie bruta -223 hectáreas netas-, que constituye la mayor actuación de suelo industrial acometida por la Junta de Castilla y León, ubicado al pie de la A-62 -Autovía de Castilla-, a 16 kilómetros de Valladolid, a 37 de Palencia, a 25 del aeropuerto de Villanubla; y en segundo lugar el inicio de la construcción de la denominada Área Central, de la red de "Enclaves CyLOG", creada por decreto 16/2007, de 22 de febrero, por el que se regula el establecimiento, organización y funcionamiento de las infraestructuras complementarias 
del transporte de mercancías y de la logística; un enclave ubicado en el límite de las provincias de Valladolid y Palencia, en los términos municipales de Venta de Baños, Villamuriel y Magaz, o lo que es lo mismo en un enclave multimodal, de alto valor estratégico al vertebrarse en él las conexiones por carretera y ferrocarril del centro con el Norte y Noroeste peninsulares. ${ }^{6}$

A estos dos grandes corredores hay que añadir un tercero, la N-122/ A-11 -autovía del Duero-; una vía que, en su continuación desde Valladolid en dirección a Soria, tan sólo se encuentra desdoblada en los primeros km, hasta Tudela de Duero, por lo que bien puede señalarse que, en al finalizar el año 2013, se presenta todavía con su trazado y tipología original, es decir, el que corresponde a una carretera convencional con algunas mejoras introducidas por la aplicación del Programa de Acondicionamiento. Ello no obstante, la Ruta del Duero-N-122 está llamada a desempeñar un papel estratégico, ya que, además mejorar la articulación regional, dado su trazado transversal, posee un notable potencial como arteria de vertebración internacional, considerados conjuntamente la N-122 y el Itinerario Principal IP-4 portugués, es decir, el Itinerario E-82 Oporto-ValladolidZaragoza.

Especial significado para la vertebración regional e incluso para el desarrollo local de Valladolid tienen otros dos ejes como son, en primer lugar, la autovía N-601/A-60 -autovía Valladolid-León-, aunque en 2013, tan sólo se había inaugurado, en la provincia de Valladolid, el tramo Valladolid-Aeropuerto de Villanubla, de 13,7 km; un tramo que parte en el enlace de la actual N-601 con la A-62 -Autovía de Castilla- y que cumple una doble función: por una parte ordenar el tramo periurbano de la vieja carretera N-601, ya parcialmente desdoblada, pero con una operatividad y funcionalidad limitada por la densidad de naves industriales de las vías de servicio paralelas a ella; y por otra parte, canalizará el tráfico del aeropuerto de Villanubla al tiempo que mejora la capacidad para atender la demanda procedente del norte de la comunidad con destino a los dos grandes Parques Comerciales del área urbana de Valladolid: Equinoccio Park, en el municipio de Zaratán y Rio Shopping en el término municipal de Arroyo de la Encomienda. Finalmente es preciso destacar el significado de la autovía de titula-

6 En 2006, la Junta solicitó al Ayuntamiento una parcela de entre 400 y 500 hectáreas bien comunicada y con conexión ferroviaria para levantar en ella naves de transporte y comunicaciones. Dicha opción fue rechazada, alegando falta de suelo para acoger este espacio, desestimando también la posibilidad de abordar una modificación del Plan General para lograr una superficie equivalente, que pasaría por unir dos áreas homogéneas, Valdechivillas y Fuente Amarga, cercanas a la nueva variante de mercancías, pero comprometidas como suelo residencial, con dos proyectos para construir 10.000 y 8.000 viviendas respectivamente. http://www.elnortedecastilla.es/pg060727/ prensa/noticias/Valladolid/200607/27/VAL-VAL-004.html 
ridad autonómica A-601 Valladolid-Segovia -Autovía de Pinares-, inaugurada en 2008, que además de conectar mediante una vía de alta capacidad dos capitales provinciales, en consonancia con el objetivo del Gobierno Regional de conectar entre sí todas las capitales de provincia de la Comunidad mediante vías de gran capacidad, tiene la virtud de enlazar con la Autopista AP-61 y la AP-6 -VillalbaAdanero- y comunicar ambos centros con el mayor enclave logístico peninsular, es decir con la Comunidad de Madrid. Constituye al tiempo una nueva alternativa para conectar Madrid con el eje Valladolid-León, actualmente en construcción y el de Valladolid-Palencia-Santander, reduciendo el tráfico de acceso a los mismos que sigue la A-6, y la A-62 entre Valladolid y Tordesillas. La ejecución de las obras se ha llevado a cabo mediante el contrato de concesión de obra pública por un plazo de 35 años, un contrato que se caracteriza por financiarse a través del sistema denominado "canon de demanda", también conocido como "peaje en la sombra" que convierte al concesionario en el encargado de la redacción del proyecto de construcción, de la construcción de la autovía y de su conservación, mantenimiento, vigilancia y explotación, asumiendo el riesgo económico de su gestión (Ruiloba, 2008). La intersección de ambas autovías -León y Segovia- con la A-62 en la ciudad de Valladolid conformará, cuando concluyan las obras en la autovía de León A-60, una estratégica encrucijada con centro en Valladolid que, sumada a la que tiene centro en Tordesillas -figura 1- dotan a la provincia y a la capital de un singular protagonismo en el transporte por carretera interregional.

\section{II.2 Infraestructuras ferroviarias para transformar el perfil funcional y estructura urbana de Valladolid.}

Tras decenios de política ferroviaria caracterizada, en el último tercio del siglo XX, por un alto grado de inercia y por la ausencia de decisiones estratégicas aplicables al conjunto de la red, el Plan de Infraestructuras del Estado 2000-2007, a través de su Programa de Infraestructuras Ferroviarias, introdujo un drástico cambio en las políticas aplicadas en el acondicionamiento de la red, perceptible ante todo en la potenciación de la alta velocidad ferroviaria (CALDERÓN, PASCUAL Y PASTOR, 2005:156), dicho plan programó una completa red ferroviaria de alta velocidad, ordenada, en lo que afecta a Castilla y León bajo la denominación de Corredor Norte-Noroeste, que parte del eje Madrid-Segovia-Valladolid/Medina del Campo, un gran eje troncal, a partir del cual se despliega el abanico de líneas de altas prestaciones destinadas a la articulación del noroeste español: ValladolidBurgos-Vitoria, L. A. V. a Cantabria -Venta de Baños-Santander-. Palencia-LeónGijón, León-Ponferrada-Monforte de Lemos y la L. A. V. a Galicia -Medina del Campo-Lubián-Orense. 
La llegada del Ave a Valladolid en diciembre de 2007 y el progreso de las obras en los tramos que prolongarán el corredor en dirección oeste -Zamora- y norte -Palencia, Burgos León dentro de la Región- y consiguientemente hacia Galicia, Asturias, Cantabria y País Vasco, ha contribuido a cambiar las relaciones de la ciudad -y por extensión la provincia- con el resto de España, de forma acompasada al despliegue del resto de la red en otras regiones españolas; pero sin duda el mayor impacto para la ciudad de Valladolid se producirá cuando culmine, previsiblemente en 2014, una de las grandes obras iniciadas en la primera década del siglo XXI: el desvío del tráfico de mercancías por las vías de ancho ibérico del bypass; un trazado de 17,5 km. concebido para una velocidad de 160 kilómetros hora, que discurre en su mayor parte en paralelo a la nueva Ronda Exterior, VA-30, en superficie en casi toda su longitud, salvo en dos kilómetros, en los que estará soterrado en un falso túnel. A esta nueva infraestructura, que dispondrá de una doble vía de ancho ibérico aunque en un tramo de seis kilómetros se ampliará con una tercera vía en ancho internacional, están asociadas a otras dos operaciones llamadas a cambiar profundamente el perfil funcional y estructura urbana de Valladolid: el traslado de los talleres de Renfe y la construcción de la nueva estación para el tráfico de mercancías y área logística anexa.

Figura 2: Nuevos talleres de Renfe (TCR) en el sector 53 del PGOU de Valladolid. Año 2013

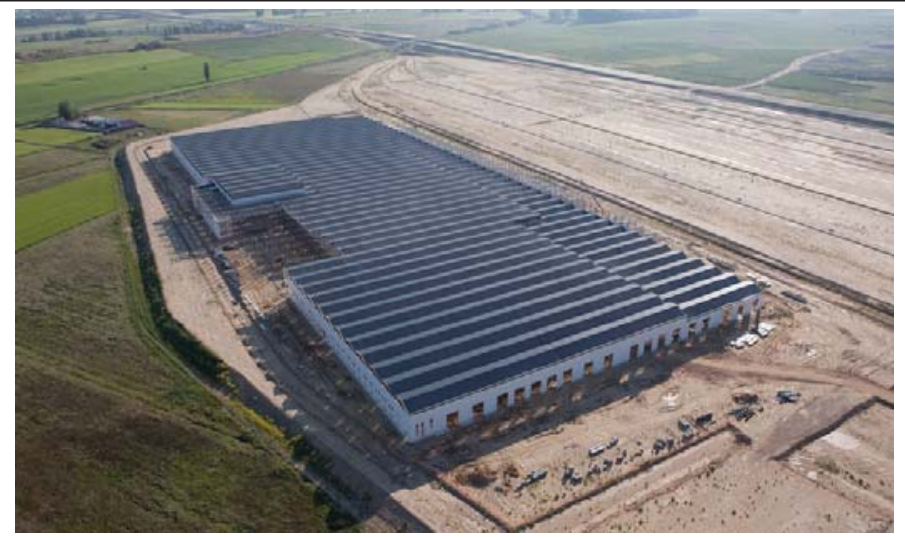

FUENTE: http://www.urbanvalladolid

El nuevo complejo ferroviario, cuya construcción se inició en 2009, y cuya inauguración está prevista para el año 2014, -figura 2- está llamado a ser uno de los elementos esenciales en el futuro del transporte y logística provincial; está ubicado dentro del término municipal de Valladolid, en el páramo de San Isidro -Área Homogénea 5/Sector 53-, sobre una superficie de 70 hectáreas y ha sido ya considerado como uno de los mayores de España, ya que contendrá no 
sólo la nueva estación de mercancías, que sustituirá a las muy modestas instalaciones existentes, ubicadas en la estación de Argales, también a Estación de la Esperanza, a la Estación de Campo Grande, y al Cargadero de Tres Hermanos; se añadirán también a esta nuevo emplazamiento el Centro de Tecnología de Vía y Redalsa, y el Taller Central de Reparaciones de Renfe-Integria, concebido para convertirse, por su dimensión e instalaciones, en el gran centro de mantenimiento para todo el Norte de España, en ancho ibérico y ancho internacional ${ }^{7}$; se ubicará también en este espacio una terminal de mercancías, que ocupará casi 23 hectáreas y contará con un lugar de estacionamiento y formación de los trenes y otro de carga y descarga apto para tránsito de contenedores, especialmente de graneles, -cereales y cementos-, entre Madrid y el Norte, y el Noroeste de España en ambos sentidos. ${ }^{8}$ Para hacer posible todo ello ha sido preciso aprobar una modificación del PGOU 2004 encaminada a transformar las 158,23 has de suelo urbanizable no delimitado y uso global residencial de este ámbito, el área homogénea 5, Páramo de San Isidro, en un sector de suelo urbanizable delimitado y uso residencial denominado Sector 53, en el que se contempla la construcción de 4.610 viviendas y cuatro nuevos sistemas generales a él adscritos, uno de los cuales, identificado como EQ 63 y con 69,90 has. -figura 2- se destina al nuevo complejo ferroviario. ${ }^{9}$

Con ello queda perfilado un nuevo gran conjunto urbano vinculado a la Red Arterial Ferroviaria de Valladolid (RAF) de nueva construcción, que precisará, no obstante, de un importante ajuste ya que, la sentencia no 233/2013 del Tribunal Superior de Justicia de Castilla y León, anuló lo que consideraba desarrollos urbanísticos innecesarios en el Área Homogénea $n^{\circ} 5$-suelo urbanizable no delimitado-, del PGOU de Valladolid, que implicaba la construcción de 4.600 viviendas, y por lo tanto se pone en riesgo el convenio suscrito el 6 de noviembre de 2002, entre el Ministerio de Fomento, la Junta de Castilla y León, y el Ayuntamiento de Valladolid, para el desarrollo de las obras derivadas de la transfor-

7 En 2010 las instalaciones logísticas de Adif, en Argales, estaban formadas por un local de $142 \mathrm{~m}^{2}, 27.030 \mathrm{~m}^{2}$ de suelo sin urbanizar y 4 playas asfaltadas con una superficie de $28.707 \mathrm{~m}^{2}$ http://www.adif.es

8 La obra fue adjudicada a la UTE Complejo Ferroviario Valladolid formada por las empresas COMSA, COLLOSA y CYCASA, por un importe total de 118.061.616 euros más IVA, a los que habría que añadir otros 3.142.151 para la prestación de asistencia técnica y coordinación en materia de seguridad y salud en las obras. Ambos contratos fueron adjudicados el 31 de marzo por la Sociedad Valladolid Alta Velocidad, formada por el Ministerio de Fomento, la Junta de Castilla y León, el Ayuntamiento de Valladolid, Renfe y ADIF. http://valladolidaltavelocidad.es

9 Orden FOM/1840/2008, de 6 de octubre, por la que se aprueba definitivamente la Modificación del Plan General de Ordenación Urbana de Valladolid en el Área Homogénea 5 de Suelo Urbanizable no delimitado «Páramo San Isidro». BOCyL Jueves, 30 de octubre 2008 
mación de la red arterial ferroviaria de Valladolid en el mismo sector. Se trata, en todo caso, de un obstáculo más en el necesario -y urgente- proceso de ordenación de la actividad de almacenamiento-transporte-logística, aprovechando la intermodalidad que permite la conexión entre las áreas de carga-descarga-manipulado de contenedores y graneles del nuevo complejo ferroviario y la VA-30 o Ronda exterior, que actuará como eje vertebrador de los grandes corredores que confluyen en Valladolid: la A-62, -autovía de Castilla- la A-11 -autovía del Duero-, la A-601 -autovía de Pinares/Segovia-, y la A-60 -autovía de León-.

En Agosto de 2013 se iniciaron las obras de ripado y renovación de vía y catenaria de la nueva línea de Alta Velocidad Valladolid-Venta de Baños-Palencia-León y de la conexión con los nuevos talleres de Renfe, para adecuar las vías del tren al sistema internacional o UIC. Esta reforma permitirá la integración ferroviaria de la ciudad con el Corredor Norte-Noroeste, habilitando la circulación de los trenes de Alta Velocidad hasta Palencia y León; al mismo tiempo se procederá a la renovación del cargadero - estación de apoyo- de Tres Hermanos, el cual contará con tres vías más de apartado. ${ }^{10}$ La culminación de estas obras, previsiblemente en 2015, acelerará el proceso de construcción del parque logístico, polígono agroalimentario y Puerto Seco de Santander en los sectores 48 y 49, Vereda de Palomares-Arenal del PGOU de Valladolid y, como fenómeno derivado, la ampliación o traslado ya sea de MERCAOLID o del enclave logístico CENTROLID perteneciente a la red CyLOG, culminando con ello el proceso de redefinición funcional del norte de la ciudad.

\section{II.3 Áreas generadoras de actividad en el entorno de Valladolid: una tupida malla de polígonos industriales articulada por las viejas y nuevas vías de alta capacidad.}

Como ya se ha señalado ut supra, además de una buena red de comunicaciones por carretera y ferrocarril, y de que todos ellos confluyen en un nudo de situación estratégica, el segundo de los elementos esenciales para la creación de centro de transportes, o de un área logística interior de alguna entidad, está relacionado con la existencia de "...polígonos industriales a los que servir, donde los transportes terrestres rápidos -ferrocarril o autopista- se encarguen de cumplir con las exigencias de los actuales intercambios comerciales ya sea a escala regional, nacional o internacional" (Morales, 2010: 213). Y este conjunto de requisitos se cumple nuevamente en Valladolid, justificando por ello la temprana

${ }^{10} \mathrm{http}: / /$ www.elnortedecastilla.es/20130826/local/valladolid/corte-trafico-pasonivel-201308262235.html 
creación de un nodo de transporte, anterior algunos años a la creación del modelo de enclaves logísticos CyLOG.

Para reforzar esta temprana vocación, las Directrices Esenciales de Ordenación del Territorio de Castilla y León aprobadas en 2008 señalan que " $L a$ acción pública debe desarrollar un sistema articulado de enclaves logísticos que fomenten y desarrollen la intermodalidad, a fin de impulsar el crecimiento y la competitividad regionales, y modernizar y cohesionar todos los modos de transporte. ${ }^{11}$ Estos enclaves deben situarse en los centros urbanos de referencia y sobre los corredores dinámicos, asociándose tanto a los espacios productivos como a la estructura de flujos de transporte, dando prioridad a los emplazamientos que garanticen un mejor cumplimiento de los criterios de intermodalidad. Y por lo que a la ciudad de Valladolid respecta se cumplen ambas condiciones, especialmente tras la puesta en servicio de la denominada Ronda exterior-VA.30-y el bypassferroviario para el tráfico de mercancías, unidas al traslado de los nuevos talleres de RENFE, ya que contribuye a reforzar el carácter multimodal de la actividad del transporte y logística, en un punto equidistante entre las grandes áreas de actividad de la ciudad y su entorno.

Sólo en el tramo de la A-62/E 80 comprendido entre Tordesillas y el límite de la provincia de Palencia se encuentran emplazados 26 polígonos industriales, a los que hay que añadir otros 18, ubicados bien en municipios del entorno de Valladolid -Santovenia, Cigales y Cabezón- o bien en municipios apoyados en otros ejes como son los de Zaratán y Villanubla, en la futura autovía Valladolid-León, A-60, Aldeamayor de San Martín y Portillo en la autovía de Segovia, A-601, o Laguna de Duero, Boecillo y Aldeamayor de San Martín en la N-601, carretera de Madrid, -ver anexo 1-.

La proximidad de las dos nuevas infraestructuras de transporte que se han construido en el sur y este de la ciudad -la VA-30 y el bypass ferroviario-, viene a reforzar el carácter multimodal de la actividad del transporte y logística en la ciudad, en un punto equidistante entre las grandes áreas de actividad de la ciudad y su entorno inmediato y que conforman lo que hemos denominado corredor industrial de Valladolid, como son, entre otros, los polígonos industriales de Las Raposas, Argales, Jalón, Carrascal, San Cristóbal, Mimbreras-Iveco y la Mora por un lado, e Industrial Casasola, Vereda de Palomares-Arenal, Las Panaderas, el Esparragal, el Arenal, Cabildo Norte, el Berrocal, el polígono industrial San Cosme, en Villanubla, y el área industrial Canal de Castilla, en Cigales, por otro.

${ }^{11}$ LEY 3/2008, de 17 de junio, de aprobación de las Directrices Esenciales de Ordenación del Territorio de Castilla y León. 
Figura 3: Grandes áreas industriales y logisticas en Valladolid

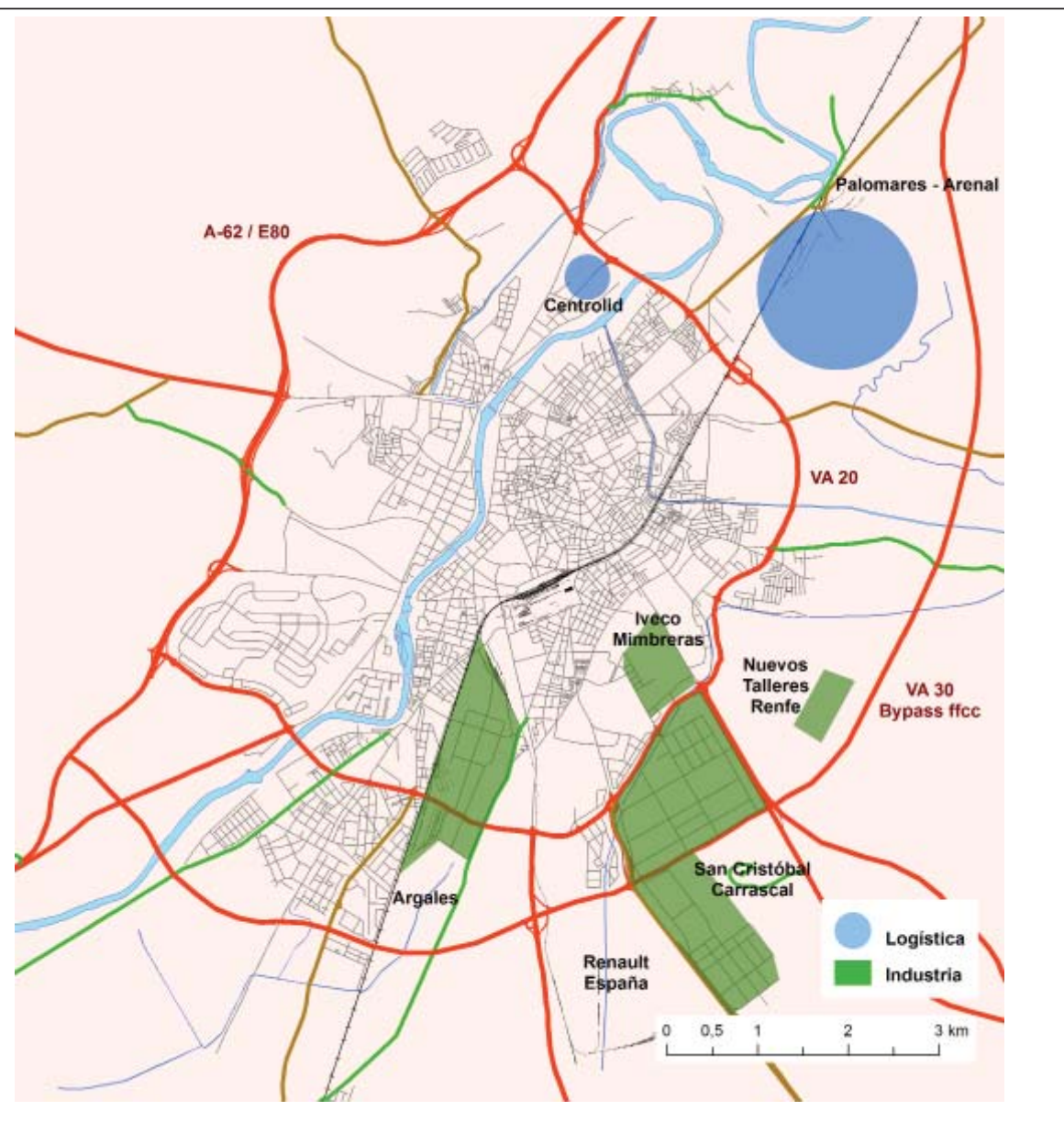

FUENTE: elaboración propia

Un conjunto de alto valor estratégico en la economía provincial que presenta, no obstante, una importante debilidad relacionada con la insuficiente capacidad del aeropuerto de Villanubla ya que, por su localización, reúne condiciones idóneas para mejorar sus condiciones de explotación y convertirse en alternativacomplemento para el tráfico de mercancías de la Comunidad de Madrid, dada su posición a escala nacional e internacional, tales como la proximidad a Madrid y al nudo Central de la red logística de Castilla y León -CyLOG-, la disponibilidad de suelo para desarrollar actividades industriales y logísticas a él vinculadas, y la conexión con los dos grandes itinerarios europeos E- 80 y E-82 y con las autovías A-60 y A-601. 
Este conjunto de atributos, unidos al tradicional caos que caracterizaba a la actividad de transporte almacenamiento en la ciudad, repartida entre los grandes polígonos industriales, y particularmente en el polígono de Argales, creado en 1963 por la Gerencia de Urbanización perteneciente al antiguo Ministerio de la Vivienda, en el que, el $80 \%$ de los establecimientos instalados - en torno a 126 en el año 2000-, desarrollaban actividades auxiliares y de servicios, destacando numerosas naves de tamaño intermedio o grande, que acogen actividades de comercio mayorista -alimentación, material eléctrico, productos metálicos, confección, materiales de construcción, muebles, electrodomésticos...- (CALDERÓN, 2003: 45). Y, aunque el segundo gran polígono industrial de la ciudad, San Cristóbal, promovido en 1977 por el antiguo Instituto Nacional de Urbanización (INUR) tuvo en su origen un porcentaje menor de actividades de transporte-almacenamiento, con el paso del tiempo esta actividad se ha ido incrementando, con la particularidad de que más de una cuarta parte de las relaciones que mantiene trascienden el ámbito local, por lo que su impacto en las infraestructuras de transporte de la ciudad es incluso superior al anterior, justificando de este modo, no solo la mejora de las misma, sino la necesidad de concentrar esta actividad en algún punto estratégico de la ciudad.

\section{EL PRIMER ESBOZO DE ORDENACIÓN DE LA ACTIVIDAD DE TRANSPORTE Y ALMACENAMIENTO EN VALLADOLID: EL PAU DEL SECTOR Nº 15, ÁREA INDUSTRIAL CABILDO SUR}

La Ley 16/1987, de Ordenación de los Transportes Terrestres, y su Reglamento -Real Decreto 1211/90-, en su Capítulo V, atribuyó la iniciativa para la creación de las denominadas Estaciones de Transporte por Carretera, de Viajeros y de Mercancías, a los Ayuntamientos, de oficio o a instancia de particulares, siendo su aprobación competencia de la Comunidad Autónoma interesada o del Estado, cuando éste fuera competente, si bien es cierto que por regla general, los Estatutos de Autonomía asumen competencias exclusivas en la materia (MINISTERIO DE FOMENTO, 2013:39). En todo caso, Comunidades y Estado podrían tomar la iniciativa con carácter subsidiario, cuando estimaran que una Estación determinada fuera necesaria y el Ayuntamiento no iniciara el procedimiento para construirla.

En consonancia con este mandato, el 4 de julio de 1990 el Ayuntamiento de Valladolid aprobó un convenio de colaboración con la Junta de Castilla y León, que tenía por objeto la construcción de un área de transporte en el sector de suelo urbanizable no programado ${ }^{\circ} 15$, industrial Cabildo Sur, del Plan General Mu- 
nicipal de Ordenación Urbana de Valladolid, aprobado definitivamente el 14 de julio de 1988, comprometiéndose aquél a la redacción y aprobación del preceptivo Programa de Actuación Urbanística. Tras someterse al complejo proceso de tramitación administrativa, que incluía la declaración de utilidad pública de los terrenos -26 propiedades- para su adquisición con destino al patrimonio público de suelo, dicho programa será aprobado definitivamente el 27 de julio de 1995 y publicado en el BOCyL el 1 de junio del mismo año. -ver anexo 3- . La superficie contemplada en él era de $411.740 \mathrm{~m}^{2}$ que perderán el uso agrícola y residencial residual, característico de un borde urbano históricamente marginado al haberse orientado el crecimiento de la ciudad en general y residencial en particular hacia el sur, y este de forma preferente. ${ }^{12}$

El destino de este suelo era diverso, ya que además los $129.344 \mathrm{~m}^{2}$ reservados "... principalmente a área de transporte para facilitar el intercambio de mercancías de entrada y salida a la ciudad sin necesidad de acceder al núcleo urbano central, eliminando así los problemas que el tráfico de vehículos ocasiona por las vías urbanas", el PAU contemplaba, además de diversos usos industriales y de servicios complementarios, una parcela en exclusiva de 117.445 $\mathrm{m}^{2}$ para la ubicación, por traslado en el año 1997, del nuevo mercado central de abastos de Valladolid -Mercaolid-, resolviendo de este modo el problema crónico de accesos, estacionamiento de vehículos pesados y carencia de servicios complementarios que afectaba al barrio de Pajarillos Bajos, (PASTOR y PASCUAL, 1994) en el que se ubicaba desde 1969, en una posición claramente disfuncional, el mercado central de abastos de Valladolid. ${ }^{13}$

Quedaba resuelta con esta propuesta la carencia de suelo destinado a dos usos globales de carácter estratégico: transporte y abastecimiento, garantizándose al tiempo la vinculación entre los mismos al eliminarse cualquier otro tipo de uso que no fuese complementario con los dos señalados, es decir, almacenamiento de mercancías, talleres de reparación de vehículos pesados, gasolinera, hostelería o administración. Al mismo tiempo, la estructura viaria interior sirve para delimitar los dos grandes usos señalados y conectarlos con el exterior a través de la llamada entonces Ronda Norte de Circunvalación, con la vieja carretera Burgos-Portugal, e incuso con el interior de la ciudad tras la construcción de un nuevo puente so-

12 “... La mayor parte de los predios tienen un uso actual de erial, junto a otros menos numerosos, de huerta, arboleda o residencial; una parte tiene uso agrícola acompañado en ocasiones por vivienda y anejos para almacenaje de los utensilios de labranza y maquinaria." Ayuntamiento de Valladolid. PAU en el sector n' 15 del PGOU "Industrial Cabildo Sur. Memoria, p. 9.

${ }^{13}$ Valladolid, PAU sector 15 Cabildo Sur. http://servicios.jcyl.es/PlanPublica 
bre el Pisuerga, denominado Santa Teresa, que tras muchos avatares, se acabará inaugurando el 25 de Marzo de 2011.

Finalmente, el 8 de octubre de 1997, el pleno del ayuntamiento de Valladolid acordó adjudicar el concurso para la construcción y explotación de la Terminal de Mercancías de Valladolid en un área reservada dentro del PAU del sector 15, industrial Cabildo Sur, a CENTROLID, reservándose el Ayuntamiento las manzanas 3, 4, 5 y 6 para su posible venta a esta entidad; en febrero de 2001 se procede a la compra de las citadas parcelas, planteando al tiempo una modificación de del plan parcial -aprobada en julio de 2001- para establecer una nueva ordenación, acompañada de cambio de uso de Industria Media por el de Almacenamiento y Transporte, compatible con las operaciones de carga, descarga y movimiento de vehículos pesados en el sector, que será aprobada definitivamente el 20 de Junio del mismo año. Esta modificación, -ver figura 4-, que convierte las manzanas 3 y 4 en la manzana $3 \mathrm{M}$, y las manzanas 5 y 6 en la supermanzana $4 \mathrm{M}$, dará mayor capacidad al futuro Centro Integrado de Mercancías, ya que el suelo reservado para el uso de transporte-almacenamiento se incrementará en más de un $50 \%$, pasando de $113.285 \mathrm{~m}^{2}$ de superficie construida a un total de 173.423 $\mathrm{m}^{2}$.

Figura 4: Modif cado $n^{\circ} 2$ del Plan Parcial de Ordenación en el sector $n^{\circ} 15 \mathrm{del}$ PGOU "industrial Cabildo Sur". Estado en 2010

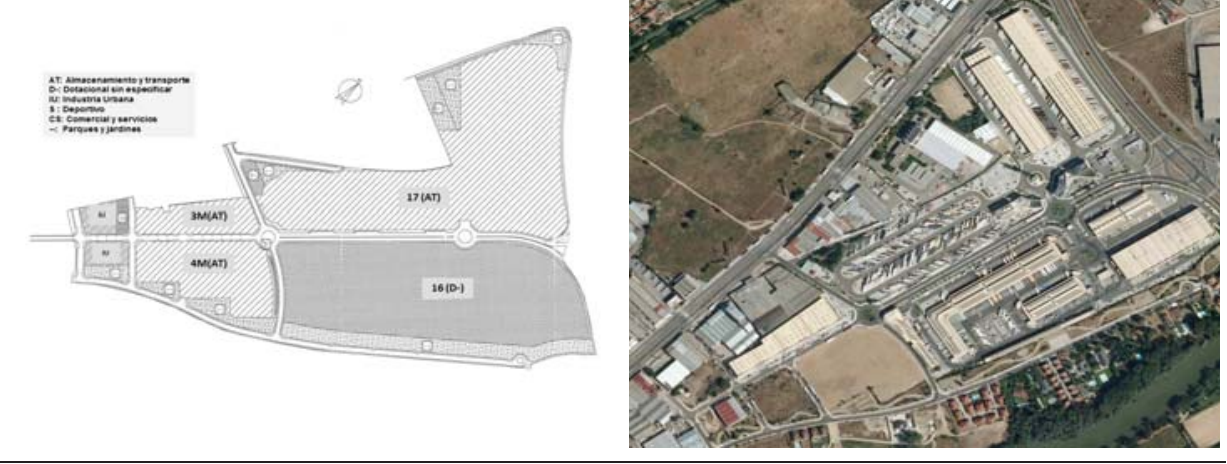

Fuente: PGOU de Valladolid de 1988. PAU del sector 15, industrial Cabildo Sur

Como es común en este tipo de desarrollos, especialmente cuando media la redacción de un PAU, el tiempo empleado para su completa urbanización fue singularmente largo - prácticamente una década-, quedando por ello prácticamente amortizada la utilidad real de un proyecto claramente insuficiente desde el origen, tanto por lo que respecta al suelo previsto para el nuevo mercado central de abastos -MERCAOLID-, apenas 12 has, como al centro integrado de mercancías 
-CENTROLID- ; y ello a pesar de que en este segundo caso, antes de dar inicio a las obras de urbanización fue preciso promover en 2001 una modificación para cambiar el uso de dos grandes parcelas - $3 \mathrm{M}$ y $4 \mathrm{M}$ en la figura 4- y pasar por ello de apenas 12 a 18 hectáreas de uso almacenamiento y transporte. Concluye este largo proceso de adaptación el 28 de octubre de 2011 al aprobarse, definitivamente, la modificación del proyecto de normalización de fincas del sector 15 "industrial cabildo sur", manzanas 3, 4, 5, 6 que además de resolver algunas diferencias de carácter catastral, permite eliminar el viario denominado calle Doblón, de forma que se pueda llevar a cabo en una macroparcela, denominada 4M una modesta y última ampliación de la superficie global de Centro Integrado de Mercancías de Valladolid, desarrollada por el operador logístico Norbert Dentressangle. El resto de las naves en la parcela $3 \mathrm{M}$, de uso almacenamiento y transporte -ver figura 4-, con una superficie comprendida entre $704 \mathrm{~m} 2$, la más pequeña, y $1.161 \mathrm{~m} 2$ la más grande son propiedad de VIVA, -Sociedad Municipal de Suelo y Vivienda de Valladolid-, estando aún disponibles en $2013^{14}$.

Finalmente, tras el derribo en 2010 de las antiguas instalaciones de Coca Cola, colindantes con CENTROLID, quedó liberado un solar de 2,5 has en el que se construirá un aparcamiento rotatorio con capacidad para 176 camiones y otros 36 automóviles y furgonetas ${ }^{15}$. Y si es cierto que, merced a ello, se ha ampliado la oferta de aparcamiento de CENTROLID, que inicialmente tenía capacidad 450 vehículos, no es menos cierto que, lamentablemente, una vez realizado este cambio, quedará agotado todo el suelo disponible en el entorno, de forma que resulta imposible dar el salto de un centro integrado de mercancías a una verdadera zona logística o área de actividades logísticas; y es que, "empeñarse en inscribir en el arbitrario límite del término municipal de Valladolid y de forma colindante con las áreas ya urbanizadas toda la dinámica de la ciudad es algo que puede resultar atractivo y cómodo a corto plazo, pero está condenado al fracaso a medio y largo plazo" (CALDERón, 2002: 27).

Con las citadas modificaciones, el ámbito delimitado para el Centro de Transporte tras el viejo acuerdo de 1990 suscrito por la Junta de Castilla y León y el Ayuntamiento reunía las condiciones esenciales para su integración en la red de infraestructuras complementarias del transporte de mercancías y la logística, aprobado por acuerdo de la junta de Castilla y León el 24 de noviembre de 2005; una vez consumada tal integración, el centro experimentará un desarrollo acelerado, de forma que en menos de una década, 2005-2013, acabará por agotar todo es espacio disponible; se hace obligado por ello analizar diversas alternativas,

14 http://www.smviva.com/\#ficha/para_empresas/33/

15 http://www.elmundo.es/elmundo/2011/03/10/valladolid/1299744528.html 
que posibiliten, o bien la ampliación o traslado de CENTROLID y que sean a la vez, consecuentes con el cambio en la tipología de suelo industrial demandado, ya sea por el sector logístico que, como es bien sabido (PonCE, 2008: 46), precisa de espacios abiertos y extensos en emplazamientos de carácter multimodal, próximos a la ciudad, y “...el sector industrial, cuyas prioridades están en los espacios pequeños, con un radio de acción que comporte, como mucho, en torno a la media hora de desplazamiento".

\section{DE ÁREA DE TRANSPORTE A ENCLAVE LOGÍSTICO: EL CEN- TRO INTEGRADO DE MERCANCÍAS DE VALLADOLID EN LA RED DE ENCLAVES LOGÍSTICOS-CYLOG-DE CASTILLA Y LEÓN}

La ley 3/2008, de 17 de junio, de aprobación de las Directrices Esenciales de Ordenación del Territorio de Castilla y León, atribuye a la logística un papel determinante en la vertebración económico-territorial de Castilla y León, confirmando con ello la estrategia regional iniciada al finalizar el año 2005; una estrategia que no concibe la actividad logística como simple gestión de carga, o de ruptura de carga, pensando sólo en función de las economías de origen o destino, o ambos, sino que pone especial énfasis en las economías del trayecto, dado el alto valor estratégico que en la economía regional tiene un sector que, en términos generales, representa más del 7\% en el VAB total de Castilla y León (AlvareZ y PARDO, 2008: 72) y que, hasta el inicio de la crisis de 2008 venía creciendo a una media del $8 \%$ anual. Como resultado de este sostenido ritmo de crecimiento, Castilla y León es en la actualidad la quinta región española por volumen de mercancía transportada por carretera, tras la Comunidad de Madrid, Cataluña, Castilla La Mancha y la Comunidad Valenciana -ver anexo 2-, siendo atendido en el espacio Regional, en 2012, por una flota registrada de 26.716 vehículos de servicio público - 19.993 pesados y 5.109 ligeros-, a los que hay que añadir otros 12.689 de servicio privado (MINISTERIO DE FOMENTO, 2010: 28).

Este elevado potencial es el que ha sido puesto en valor para superar la inercia, propia del espacio central en un territorio que hay que atravesar necesariamente, como Castilla y León, para dar el salto de la simple gestión de flujos a la creación de valor a partir de los mismos, siendo este en parte el objetivo del Modelo CYLOG de infraestructuras complementarias del transporte de mercancías y la logística, aprobado por acuerdo de la Junta de Castilla y León el 24 de noviembre de 2005 -ver cuadro 1-y formalizado mediante el Decreto 16/2007, 
de 22 de febrero, por el que se regula el establecimiento, organización y funcionamiento de los denominados «Enclaves CyLOG».

\section{IV.1 Un ambicioso modelo infraestructuras complementarias del transporte de mercancías y de la logística: originalidad y limitaciones de la red de «Enclaves CyLOG».}

Pese a su carácter relativamente reciente, y pese a que no se ha podido completar conforme a los plazos previstos como consecuencia de la profundidad de la crisis económica, el modelo ha sido analizado y sometido a evaluación en diversas ocasiones, ya sea considerando la idoneidad de su estructura de enclaves (LóPEZ y Benito: 2012), su oportunidad en las directrices básicas de Ordenación del Territorio de Castilla y León (CALDERón y Pascual, 2007) (Rivas, 2008), o su vinculación con la actividad del transporte de mercancías por carretera (CECALE, 2007).

El modelo, impulsado por el Gobierno regional de Castilla y León, y que se financiará, una vez alcanzados los objetivos de desarrollo, con sus propios recursos, opera de forma autónoma; se articula en torno a tres tipos de sociedades instrumentales: las gestoras de enclaves (4 en 2012), las sociedades logísticas y las centrales de compras (9 en 2012) y comprende 15 encaves logísticos: Aranda de Duero, Enclave Logístico Regional, Arévalo, Ávila, Benavente, Ponferrada -El Bierzo-, Burgos, León, Miranda de Ebro, Palencia, Salamanca, Segovia, Soria, Valladolid y Zamora; todas las infraestructuras y equipamientos son de titularidad pública y son explotadas por el sector privado mediante concesión administrativa.

El modelo de financiación hasta su total despliegue pretendía desarrollarse en dos periodos: 2006-2011 y 2011-2015. En el primero se acometieron las inversiones necesarias para la construcción o ampliación de enclaves, es decir, su urbanización, accesos, viales, construcción de naves, diseño del plan de negocio etc...) y se priorizaron las infraestructuras asociadas al modo dominante -la carretera- ya que cuando se aprobó el modelo, en 2006, más del 98 por 100 de las mercancías se transportaban por carretera. En el segundo periodo -201115- estaba - estaba- previsto completar los enclaves y fomentar la intermodalidad ferroviaria, si bien ambos objetivos están paralizados como consecuencia de la crisis económica de la segunda mitad de la primera década del siglo XXI. La financiación realizada en el denominado modelo básico -sin desarrollo ferroviario- es de 1.125 millones de euros, de los que 225 eran públicos y 900 privados. Pero en 2012 solo ocho de los quince enclaves estaban operativos: Valladolid, Salamanca, Palencia, Benavente, León, Ávila, Burgos y Soria. Dos enclaves se 
encontraban en fase de desarrollo: Miranda de Ebro y Área el Central (Venta de Baños-Villamuriel) y otros cinco enclaves se encontraban aún en proyecto: Aranda de Duero, Arévalo, Segovia, Zamora y Ponferrada. -ver cuadro 2-.

\begin{tabular}{|c|c|}
\hline \multicolumn{2}{|r|}{ Cuadro1: Principales hitos normativos en el proceso de creación de la red CyLOG } \\
\hline Año & Legislación/normativa \\
\hline 2005 & $\begin{array}{l}\text { Modelo CyLOG de infraestructuras complementarias del transporte de mer- } \\
\text { cancías y la logística aprobado por acuerdo de la Junta de Castilla y León el } \\
24 \text { de noviembre de } 2005\end{array}$ \\
\hline 2007 & $\begin{array}{l}\text { Decreto } 16 / 2007 \text {, de } 22 \text { de febrero, por el que se regula el establecimiento, } \\
\text { organización y funcionamiento de las infraestructuras complementarias del } \\
\text { transporte de mercancías y de la logística, «Enclaves CyLOG». }\end{array}$ \\
\hline 2008 & $\begin{array}{l}\text { Orden FOM/1570/2008, de } 14 \text { de agosto, por la que se regula la estruc- } \\
\text { tura y el régimen de funcionamiento del Registro de Enclaves Logísticos } \\
\text { «CyLOG». }\end{array}$ \\
\hline 2008 & $\begin{array}{l}\text { LEY } 3 / 2008 \text {, de } 17 \text { de junio, de aprobación de las Directrices Esenciales de } \\
\text { Ordenación del Territorio de Castilla y León. }\end{array}$ \\
\hline 2008 & $\begin{array}{l}\text { Resolución de } 7 \text { de mayo de } 2008 \text {, de la Gerencia Regional de Justicia, de } \\
\text { la Consejería de Interior y Justicia, por la que se acuerda la inscripción de } \\
\text { la «Fundación CyLOG» en el Registro de Fundaciones de la Comunidad de } \\
\text { Castilla y León. }\end{array}$ \\
\hline 2008 & $\begin{array}{l}\text { Orden FOM/1570/2008, de } 14 \text { de agosto, por la que se regula la estruc- } \\
\text { tura y el régimen de funcionamiento del Registro de Enclaves Logísticos } \\
\text { "CyLOG". }\end{array}$ \\
\hline 2009 & $\begin{array}{l}\text { Resolución de la Dirección General de Transportes de } 7 \text { de abril de } 2009 \text {, por } \\
\text { la que se dicta la Instrucción Técnica n } 1 / 2009 \text { que establece criterios para } \\
\text { la emisión por la Asociación CyLOG de informes técnicos relativos a los } \\
\text { "Enclaves Logísticos CyLOG" y a su categorización. }\end{array}$ \\
\hline 2009 & $\begin{array}{l}\text { Resolución de la dirección general de transportes de } 7 \text { de abril de } 2009 \text {, por } \\
\text { la que se dicta la instrucción técnica } n^{\circ} 1 / 2009 \text { que establece criterios para la } \\
\text { emisión por la asociación CyLOG de informes técnicos relativos a los "en- } \\
\text { claves logísticos CyLOG" y a su categorización. }\end{array}$ \\
\hline
\end{tabular}

En conjunto, la valoración global de este modelo es muy positiva, pudiendo considerarse como una buena práctica en el ejercicio de ordenar un territorio tan extenso como Castilla y León; resulta especialmente destacable la forma en que contribuye a la consolidación del corredor E-80/A-62, de Miranda de Ebro a Fuentes de Oñoro por Briviesca, Burgos, Venta de Baños, Valladolid, Tordesillas, Salamanca y Ciudad Rodrigo, como corredor de desarrollo económico regional, así como la puesta en valor del potencial del corredor del Duero, de Zamora a Soria por Toro, Tordesillas, Valladolid, Peñafiel, Aranda de Duero y El Burgo de 
Osma y, en general, la mejora de la integración de procesos logísticos con las comunidades de Cantabria, Asturias, Galicia y País Vasco.

\begin{tabular}{|c|c|c|c|c|c|}
\hline \multicolumn{6}{|c|}{ Cuadro 2: Estado de la red CyLOG. Enclaves operativos y en proyecto en 2011} \\
\hline & $\begin{array}{l}\text { Área } \\
\text { logística } \\
\mathrm{m}^{2}\end{array}$ & $\begin{array}{l}\text { Área ad- } \\
\text { ministrati- } \\
\text { va y servi- } \\
\text { cios m² }\end{array}$ & $\begin{array}{l}\text { Viales } \\
\text { y zonas } \\
\text { verdes } \\
\mathrm{m}^{2}\end{array}$ & $\begin{array}{l}\text { Parking } \\
\mathrm{n}^{\mathrm{o}} \text { vehí- } \\
\text { culos }\end{array}$ & $\begin{array}{l}\text { Total } \\
\text { has. }\end{array}$ \\
\hline Benavente (CTB) & 35.640 & 17.520 & 56.500 & 620 & 21,23 \\
\hline León (Cetile) & 14.625 & 1.950 & 48.900 & 260 & 25,23 \\
\hline Palencia. (Cetrapal) & 6.347 & 400 & 3.320 & 160 & 27,54 \\
\hline Salamanca. (Zaldesa) & 17.800 & 5.191 & 10.470 & 1.086 & 66,90 \\
\hline Valladolid. (Centrolid) & 38.934 & 21.948 & 68.182 & 1.086 & 21,00 \\
\hline Avila. (Provilsa) & 12.400 & 1.120 & 38.000 & 2.211 & 45,32 \\
\hline Burgos. (CTB Burgos) & 73.700 & 14.125 & 139.000 & 550 & 30.08 \\
\hline Soria. (Uesoria) & 6.584 & 4.874 & & 960 & 70,07 \\
\hline \multicolumn{6}{|l|}{ Enclaves en proyecto } \\
\hline Localidad & $\begin{array}{l}\text { Aranda } \\
\text { Duero }\end{array}$ & Arévalo & Segovia & Zamora & $\begin{array}{l}\text { Ponferra- } \\
\text { da }\end{array}$ \\
\hline Has. Previstas & 20 & 20 & 20 & 69,90 & 100 \\
\hline
\end{tabular}

El modelo se apoya en tres grandes pilares como son: las centrales de compras, los acuerdos con grandes operadores logísticos nacionales e internacionales y los convenios con las autoridades portuarias para la creación de los denominados Puertos Secos. Las Centrales de Compras, constituyen un ejemplo de los servicios avanzados que proporciona el sistema; pueden definirse como el acuerdo que suscriben una serie de empresas para comprar de manera conjunta determinados productos propios de su actividad profesional, es decir, que desarrolla una actividad de intermediación comercial referente a suministros y servicios prestados a empresas del sector del transporte de mercancías y viajeros; al finalizar 
el año 2009 estaban ya operativas 9 centrales de compras, a las que pertenecen 124 empresas, ubicadas en Valladolid, Salamanca, Palencia, León, Segovia, El Bierzo, Miranda, Benavente y Soria, encontrándose en fase de incorporación las de Ávila, Burgos, Aranda de Duero y Zamora ${ }^{16}$.

Es de destacar en segundo lugar a la incorporación de grandes operadores logísticos de ámbito internacional a su red CyLog con el objetivo de ampliar su potencialidad destacando los casos de: Ceva Logistics, Norbert Dentressangle Gerposa, DB Schenker, Geodis BM, DHL Supply Chain, Carreras Grupo Logístico, Rhenus Logistics, Sintax Logística, FCC Logística, y Tradisa. Y finalmente junto a las centrales de compras, y la incorporación de operadores logísticos juegan un papel determinante los acuerdos suscritos por la asociación CyLoG con diversas autoridades portuarias españolas y portuguesas -Marín y Ría de Pontevedra, La Coruña, Gijón, Santander, Bahía de Algeciras, Valencia, Barcelona, Figueira da Foz, Aveiro y Leixoes- y la creación de una red de cinco puertos secos, vinculados a otros tantos muelles del Cantábrico y Atlántico (Portugal), Pancorbo (Burgos), Salamanca y Valladolid, que unirán a los de Venta de Baños (Palencia) y Burgos. Completarán la capacidad de almacenaje de mercancías, 'hinterland', de los puertos marítimos, liberando espacio en las instalaciones portuarias. Además, servirán de punto intermedio de la red de distribución, en la meseta, al estar conectados con sus terminales en la costa y disponer de un servicio de aduana, que agiliza la salida de las mercancías contribuyen a fomentar la intermodalidad al tiempo que se pone en valor la infraestructura de comunicación disponible, especialmente en los grandes ejes viarios descritos ut supra.

En otro orden de cosas, el modelo ha permitido ordenar el tráfico-aparcamiento y las operaciones de carga-descarga de vehículos pesados en áreas específicas, en las que apenas se generan externalidades negativas relacionadas con el ruido, la contaminación o la congestión de tráfico. En no pocos casos (Salamanca, Valladolid... a los enclaves se asocia por proximidad los antiguos mercados centrales, con lo que se facilita las operaciones de aprovisionamiento reduciendo distancias y tiempo empleados en operaciones rutinarias o periódicas; y liberando en cierto modo de parte de esta actividad a los grandes polígonos industriales, convertidos de facto en centros de almacenamiento y venta a proveedores locales, es decir, en micro-plataformas logísticas de escala urbana.

${ }^{16}$ En 2009 las compañías asociadas a estas centrales de compras registraron un consumo de casi 50 millones de litros de carburante y tienen la titularidad de cerca de 5.000 líneas de teléfono móvil. Además, gestionan una flota global de 6.600 vehículos, alcanzando una facturación conjunta de casi 2.000 millones de euros y cuentan con una plantilla de 9.550 trabajadores, a los que se añaden otros 1.260 empleos indirectos. www.asociacioncylog.com 
Pero, el modelo CyLOG, en cuyo desarrollo se está haciendo un notable esfuerzo inversor, presenta diversas limitaciones, partiendo del óptimo que identifica una área logística cuando esta dispone de amplias extensiones de suelo, con objeto de facilitar y garantizar la operatividad de los vehículos y operaciones de carga en general en el interior de los recintos; y también cuando está emplazada en áreas donde se cumpla el mayor grado de intermodalidad, y finalmente y como complemento o alternativa, cuando está situada en entornos urbanos y económicos muy dinámicos.

Frente a este óptimo, el modelo CyLOG aparece apoyado excesivamente en la carretera -a veces sólo en la carretera-, apreciándose asimismo y sin duda por efecto de la crisis, una notable asincronía en la inversión-ordenación de las carreteras y las áreas con actividad logística. Por otra parte, en no pocos casos, las áreas o enclaves logísticos son espacios acotados y finitos, sin posibilidades de ampliación como la de Valladolid -en realidad se trata de un Centro Integrado de Transporte-, que debe su mayor rango en la escala de la logística al contiguo centro de Mercaolid, que es en realidad donde se realizan múltiples operaciones operaciones de valor añadido ${ }^{17}$. A mayor abundamiento, por su posición, marcadamente intraurbana, una parte de las citadas áreas no pueden ofrecer suelo urbanizado o naves en alquiler a precio competitivo con relación con las plataformas cercanas -de otras regiones-y a otras áreas industriales de la ciudad. Este hecho ha dado lugar a la creación de pequeñas tramas logísticas de implantación difusa, apoyadas en carreteras o núcleos rurales colindantes con precios más competitivos.

Tampoco se advierte estrategia alguna para incentivar el traslado a las áreas logísticas de nuevo diseño, de los grandes centros de almacenamiento-distribución que todavía se hallan dispersos entre tramas residenciales o industriales de las ciudades. El caso de los polígonos de primera generación, los mercados centrales, y las áreas de asentamiento espontáneo en las carreteras, que en conjunto constituyen el mayor problema para algunas áreas urbanas. En este sentido sería preciso considerar la conveniencia de impulsar la creación de plataformas

${ }^{17}$ En el mercado central de abastos de Valladolid-MERCAOLID, se encontraban, en 2011, asentadas 27 empresas en del sector de frutas, 30 en el de verduras, 19 en el de pescados y 38 empresas de actividades diversas en un área denominada zona de actividades complementarias; La superficie de esta zona es de $42073 \mathrm{~m}^{2}$, que representa cerca del $50 \%$ de la superficie total del centro, asentándose en ella actividades que aportan valor añadido a las empresas mayoristas (manipulación, transformación, envasados, almacenamiento con frío... etc.), para el desarrollo de servicios complementarios a la atención de los usuarios (alquiler de frío, servicios especializados) o para incorporar nuevos sectores, con un carácter similar a la actividad de las zonas de actividad logística o plataformas logísticas. MERCAOLID, Memoria anual 2011. http://www.mercaolid.es/ memoriamercaolid11.pdf.pdf 
de distribución en el interior los grandes núcleos urbanos que vayan más allá de los tradicionales mercados centrales y que agrupen, aprovechando probablemente el remodelado de viejos polígonos industriales semiamortizados, todas las áreas de carga/descarga/distribución de mercancías. La optimización de los recorridos, la proximidad y la necesaria diversidad funcional que contempla la ley de urbanismo de Castilla y León hace muy aconsejable el planteamiento de este modelo de organización intraurbana, que además se refuerza en el artículo 38.c de las Directrices Esenciales de Ordenación del Territorio de Castilla y León, en el que se apuesta por la necesidad de "desarrollar sistemas públicos de transporte, al servicio de unidades urbanas homogéneas y moderando el acceso a espacios centrales con sistemas periféricos de aparcamiento e intercambio."

\section{IV.2 Una buena práctica, pero con fecha de caducidad: desarrollo y colmatación del Centro Integrado de Mercancías de Valladolid - CENTROLID-.}

El Centro Integrado de Mercancías de Valladolid, CENTROLID, ha sido desde su inauguración en 1999 hasta 2012 uno de los enclaves de referencia de la red CyLOG, por tamaño y dinamismo. Como ya se ha señalado, se trata de un centro de modestas dimensiones ya que cuenta con una superficie bruta de $184.478,40 \mathrm{~m}^{2}$, de los que $145.428,40 \mathrm{~m}^{2}$ corresponden a la superficie construida -ver cuadro 3-. Dispone, como elementos más significativos, de una superficie logística de $125.316 \mathrm{~m}^{2}$, en las que operan múltiples empresas de entre las que sobresalen la Central lechera Vallisoletana, Grupo San Cayetano, Industrias lácteas Vallisoletanas, Ipes Ibérica, Michelín España y Portugal, Mondi Packaging, Natur Feed, S.A o Renault España; dispone también de un área de estacionamiento vigilado para vehículos pesados de $27.201,99 \mathrm{~m}^{2}$, con capacidad para 449 vehículos pesados y 475 ligeros, que presenta un alto índice de ocupación y del que son usuarios alguna de las grandes empresas del sector como Argach-Buru, S.A, Fernandez Casal E Hijos, S.L, Logística Tam España, S.L., O.L.T., S.L, Pardo Freijo, S.A, Sota E Hijos, S.L, Tracysa, S.L, Transportes Boada, S.L, Transportes Hernanz, S.A, Trive, S.L. 
Cuadro 3: Distribución de usos en el Centr o Integrado de Mercancías de Valladolid. Año 2013

\begin{tabular}{|l|r|}
\hline SUPERFICIE LOGISTICA & $\mathrm{m}^{2}$ \\
\hline Naves de logística & $62.964 \mathrm{~m}^{2}$ \\
\hline Muelles & $27.409 \mathrm{~m}^{2}$ \\
\hline Zonas verdes & $10.400 \mathrm{~m}^{2}$ \\
\hline Viario & $24.543 \mathrm{~m}^{2}$ \\
\hline Total Superficie & $125.316 \mathrm{~m}^{2}$ \\
\hline SUPERFICIE ADMINISTRATIVA & \\
\hline Total superficie administrativa & $23.807 \mathrm{~m}^{2}$ \\
\hline SUPERFICIE DE SERVICIOS & $11.829 \mathrm{~m}^{2}$ \\
\hline Total superficie de servicios & \\
\hline SUPERFICIE DE ESTACIONAMIENTO & 283 \\
\hline Total plazas ligeros & 707 \\
\hline Total plazas pesados & $77.928 \mathrm{~m}^{2}$ \\
\hline Total superficie & \\
\hline FuENTE: www.centrolid.com 01.10.2013 & \\
\hline
\end{tabular}

El proceso de desarrollo de CENTROLID fue tan vertiginoso que en 2012 tenía ya comprometida toda la edificabilidad del sector tras la construcción de la nueva área logística de Norbert Dentressangle en una parcela de 40.000 metros cuadrados con la definitiva desaparición de la calle Doblón, ubicando en ella una nueva nave de cerca de 8.000 metros cuadrados para sus operaciones, con 47 muelles de carga y descarga de vehículos y 1.000 metros para oficinas, con un coste global cercano a los 5 millones de euros. Tras esta operación la citada empresa, una de las mayores del sector logístico europeo, duplicó el espacio que ocupaba en el enclave logístico DE CENTROLID , aumentando con ello en 30 personas más de la plantilla hasta alcanzar un total de 230 trabajadores. ${ }^{18}$ Una solución transitoria, que sirve tan solo para resolver el problema algunos años más, es la que se ha alcanzado tras el derribo de las antiguas instalaciones de Coca-Cola que se encontraban junto a CENTROLID; en este solar, de 2,5 hectáreas, se pretende construir un aparcamiento con capacidad para 176 camiones y otros 36 automóviles y furgonetas, según proyecto aprobado por el Ayuntamiento en diciembre de 2010.

${ }^{18} \mathrm{http}$ :/Www.castillayleoneconomica.es/noticia/norbert-dentressangle-destina-46millones-duplicar-su-espacio-log\%C3\%ADstico-en-valladolid 
Cuadro 4: Una buena, pero limitada, práctica urbana. Ventajas y limitaciones del emplazamiento del CIM de Valladolid (CENTROLID)

\begin{tabular}{|c|c|}
\hline ASPECTOS POSITIVOS & ASPECTOS NEGATIVOS \\
\hline $\begin{array}{l}\text { 1. Ha servido para canalizar el tráfico de } \\
\text { mercancías del denso tejido industrial de } \\
\text { Valladolid y su entorno creando fuertes } \\
\text { sinergias entre las actividades vinculadas } \\
\text { al transporte en todas sus escalas, desde } \\
\text { la local a la internacional. }\end{array}$ & $\begin{array}{l}\text { 2. Es un espacio de crecimiento limita- } \\
\text { do por la Ronda interior -VA20-, el río } \\
\text { Pisuerga y el carácter residencial conso- } \\
\text { lidado del oeste - barrio de la Victoria- }\end{array}$ \\
\hline $\begin{array}{l}\text { 3. Ha ganado presencia como espacio } \\
\text { necesario y alternativo a la actividad de } \\
\text { transporte frecuente en los viejos polígo- } \\
\text { nos industriales del interior de la ciudad. }\end{array}$ & $\begin{array}{l}\text { 4. Genera diseconomías derivadas de la } \\
\text { proximidad al tejido urbano y de la con- } \\
\text { gestión de la Ronda Interior - corredor } \\
\text { de carga de operatividad limitada- para } \\
\text { gran parte de las áreas industriales de } \\
\text { Valladolid y su entorno--. }\end{array}$ \\
\hline $\begin{array}{l}\text { 5. Ha concentrado una parte sustancial } \\
\text { de la actividad del transporte y almace- } \\
\text { namiento, con lo que de mejora para el } \\
\text { medio ambiente urbano y sostenibilidad } \\
\text { en general. }\end{array}$ & $\begin{array}{l}\text { 6. Insuficiente conexión con la A-62, } \\
\text { (E-80). Punto de concentración de acci- } \\
\text { dentes por alta densidad de tráfico y la } \\
\text { conexión con las factorías de Michelín y } \\
\text { Tafisa. }\end{array}$ \\
\hline $\begin{array}{l}\text { 7. Ha actuado como complemento ne- } \\
\text { cesario del mercado central de abastos } \\
\text {-MERCAOLID-, convirtiéndose en cier- } \\
\text { to modo en una plataforma idónea para } \\
\text { una parte de la actividad logística urbana } \\
\text { desarrollada desde } 1997 \text { en él. }\end{array}$ & $\begin{array}{l}\text { 8. Dificultad para una adecuada conexión } \\
\text { con la nueva área industrial y logística: } \\
\text { Parque agroalimentario a causa de viario } \\
\text { convencional, las vías del ferrocarril o un } \\
\text { gran equipamiento de imposible traslado: } \\
\text { el cementerio de El Carmen. }\end{array}$ \\
\hline $\begin{array}{l}\text { 9. Ha servido para impulsar una crecien- } \\
\text { te presencia de operadores logísticos en } \\
\text { Valladolid en función de su carácter de } \\
\text { Capital Regional. }\end{array}$ & $\begin{array}{l}\text { 10. Carece de acceso a la nueva infraes- } \\
\text { tructura ferroviaria. }\end{array}$ \\
\hline $\begin{array}{l}\text { 11. Se ha constituido en una buena prác- } \\
\text { tica urbana atendiendo a su carácter pla- } \\
\text { nificado, a su capacidad para adaptarse a } \\
\text { los nuevos requerimientos del sector del } \\
\text { transporte, a su capacidad para crear si- } \\
\text { nergias con actividades complementarias. }\end{array}$ & $\begin{array}{l}\text { 12. No tiene capacidad para atender los } \\
\text { requerimientos del nuevo puerto seco de } \\
\text { Santander }\end{array}$ \\
\hline $\begin{array}{l}\text { 13. La mayor virtud de esta iniciativa se } \\
\text { encuentra en el hecho de que cumplió } \\
\text { con su objetivo al agotar todo su po- } \\
\text { tencial de crecimiento, con actividades } \\
\text { vinculadas al transporte y logística ex- } \\
\text { clusivamente. }\end{array}$ & $\begin{array}{l}\text { 14. Puede resultar suficiente para atender } \\
\text { los requerimientos del momento, actua- } \\
\text { les, pero no puede adaptarse a nuevas } \\
\text { exigencias: ni por capacidad de almace- } \\
\text { naje o muelles de carga, ni por capacidad } \\
\text { para desencadenar efectos multiplicado- } \\
\text { res en su entorno. }\end{array}$ \\
\hline
\end{tabular}


Apenas quince años después de su creación, y sin que se haya amortizado -por el escaso tiempo transcurrido- una inversión tan considerable como la que exigió la construcción del Centro Integrado de Mercancías -más tarde enclave logístico-, se han puesto de manifiesto las enormes ventajas derivadas de la concentración de esta actividad, tales como el haber contribuido a canalizar el tráfico de mercancías del denso tejido industrial de Valladolid y su entorno creando fuertes sinergias entre las actividades vinculadas al transporte en todas sus escalas, desde la local a la internacional; en el mismo sentido, CENTROLID ha actuado como complemento necesario del mercado central de abastos -MERCAOLID-, convirtiéndose en cierto modo en una plataforma idónea para una parte de la actividad logística urbana desarrollada desde 1997, habiendo servido también para impulsar una creciente presencia de operadores logísticos en Valladolid en función de su carácter de Capital Regional por lo que bien puede considerarse como una buena práctica urbana atendiendo a su carácter planificado, a su capacidad para adaptarse a los nuevos requerimientos del sector del transporte, y a su capacidad para crear sinergias con actividades complementarias.

Pero al tiempo se han puesto ya en evidencia también algunas de las mayores limitaciones que presenta el caso analizado, como paradigma de lo que ha sucedido en otras muchas ciudades españolas, en relación con el tamaño y localización de estas grandes infraestructuras; destacan es este aspecto su carácter reducido y finito, lo que equivale al estancamiento de su desarrollo económico, al perderse nuevas oportunidades de negocio vinculadas al desarrollo industrial y logístico de la ciudad (Área de Actividades Canal de Castilla en Cigales-Cabezón, polígono agroalimentario y Puerto Seco de Santander en el polígono logístico Industrial de Vereda de Palomares-Arenal, la nueva Estación de Mercancías etc...) $)^{19}$; esta situación se ha traducido ya en la elaboración de un nuevo plan de expansión, que pasaría por el traslado de CENTROLID al área de Palomares, por ser la más eficiente, dentro del término municipal de Valladolid, para la expansión de esta actividad empresarial. Se da además la circunstancia de que algo similar le sucede ya a las contiguas instalaciones del mercado central de abastos de Valladolid, MERCAOLID, por lo que la solución que habrá que adoptar a corto plazo pasa necesariamente por trasladar una de las dos instalaciones al cercano polígono industrial y logístico de Vereda de Palomares en el que el Ayuntamiento ha adquirido ya diversos lotes de suelo y se ha comprometido a participar en la entidad público-privada encargada de la explotación del futuro Parque logístico-

19 "Centrolid busca terrenos junto al futuro complejo ferroviario tras quedarse sin espacio en el Cabildo" Jueves 13.12.2013 http://www.eldiadevalladolid.com 
agroalimentario, como medida de control del precio del suelo y de intervención en el mercado. ${ }^{20}$

\section{IV.3 Nuevas infraestructuras, nuevas oportunidades: hacia la reordenación de las actividades logísticas en el término municipal de Valladolid.}

Además del área logística de Renfe, vinculada al bypass ferroviario, como ya se ha analizado ut supra, en los últimos meses de 2013 se encontraba en fase de aprobación el nuevo polígono agroalimentario industrial y logístico de Vereda de Palomares y Arenal, en el noreste de la ciudad, entre la ronda interior y exterior-VA-30-; la construcción de la nueva fábrica de Lesaffre Ibérica, S.A., acogida al programa de reubicación de empresas y la ubicación del área logística de la empresa Queserías Entrepinares, en el polígono industrial denominado NICAS, que ocupa el solar de una antigua fábrica de fertilizantes y en la que el ayuntamiento disponía aún, en 2013, de una parcela a la venta de uso Industria General, de $35.906 \mathrm{~m} 2$ equivalentes a $26.929 \mathrm{~m}^{2}$ de edificabilidad en planta más dos alturas $\left(0,75 \mathrm{~m}^{2} / \mathrm{m}^{2}\right.$ de índice de edificabilidad)-ver figura 6.1 y $6.2-$, constituyen en cierto modo la avanzadilla estratégica que tiene por objeto la creación de un gran polígono industrial y logístico al Norte de la ciudad; la adquisición programada de suelo por parte del Ayuntamiento para poder convertirse en su promotor, parece que pueden favorecer esta estrategia que, de materializarse, vendrá a reforzar el perfil logístico del uso suelo entre rondas del noreste y este de Valladolid, con la ventaja de la intermodalidad que se alcanzaría tras la construcción de un ramal ferroviario desde la variante de mercancías en construcción en 2010. Se trata de un emplazamiento de alto valor estratégico, que recuperaría la función industrial y logística que ya tenía atribuida en las Directrices de Ordenación del territorio de Valladolid y su entorno del año 2001 y en el PGOU de Valladolid de 2004, toda vez que era el lugar elegido en principio para la construcción de los talleres y estación de mercancías, más tarde trasladados, en un notable error estratégico de la ciudad, al Área Homogénea no 5 , Páramo de San Isidro.

${ }^{20}$ http://www.elmundo.es/elmundo/2011/05/16/valladolid/1305546990.html 
Figura 5: Plan parcial de los Sectores 48 Arenal y 49 Vereda de Palomares.

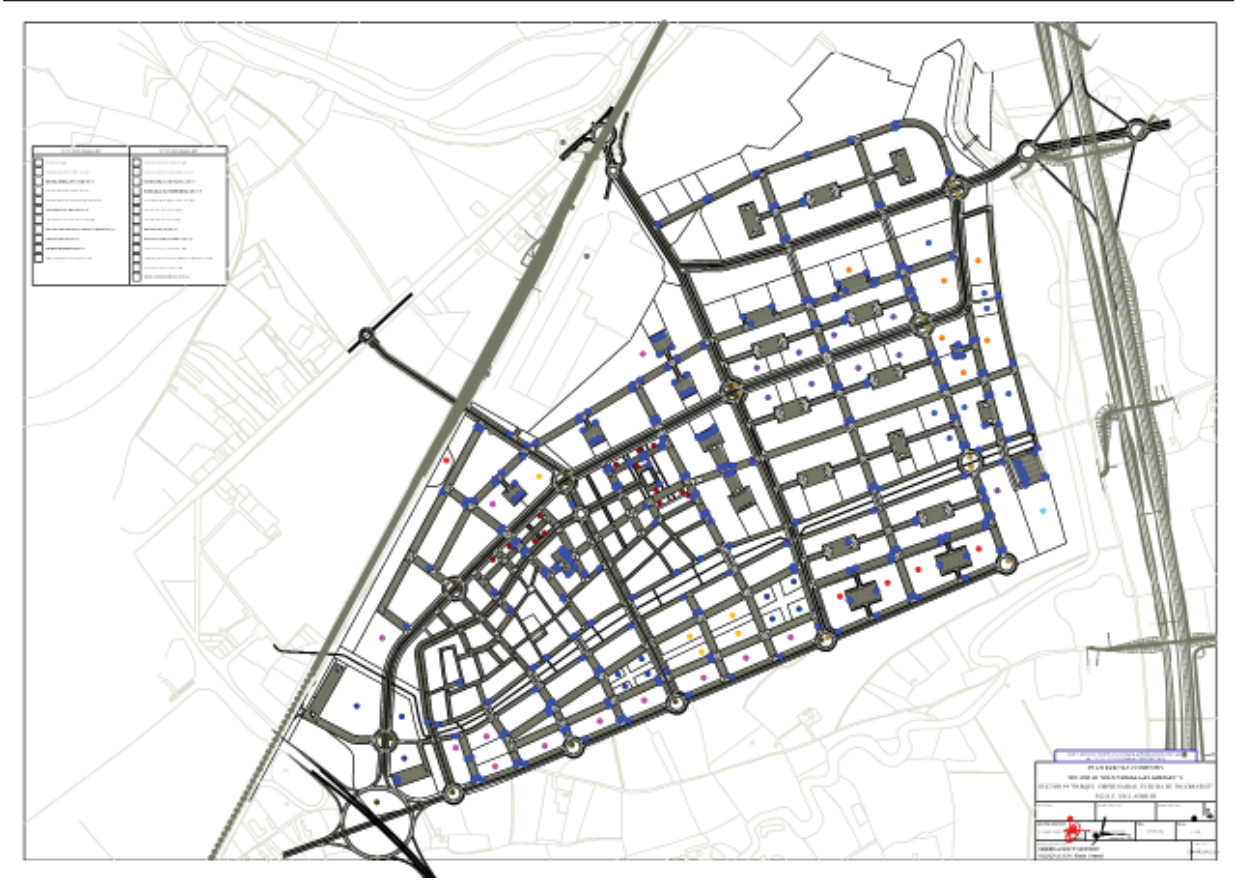

FuENTE: Documento de aprobación inicial del PGOU de Valladolid. Año 2012

Para desarrollar esta estrategia, el 29 de junio de 2012 el Ayuntamiento de Valladolid procedió a la aprobación inicial del plan parcial de los sectores 48 (Industrial Las Arenas,) y 49 (Parque Empresarial Vereda de Palomares, al noreste de la capital, junto a la vía férrea y el Canal del Duero - ver figura 5-, con una superficie de 133 y 138 hectáreas, respectivamente -69 y 72 has. de aprovechamiento lucrativo- (ver figura 6.2 y 6.3 ) ; contará con accesos directos al desvío ferroviario de mercancías y a las carreteras VA-20 o Ronda Interior Norte, VA-30 o Ronda Exterior Este con enlace a la Autovía A-62 (Burgos-Portugal) y VA113 (carretera de Cabezón) ${ }^{21}$; en ambos sectores estará ubicado el Puerto Seco de Santander, posibilitando además una mejora -por traslado o ampliación- de MERCAOLID o del enclave logístico CyLOG de Valladolid -CENTROLID-

${ }^{21}$ El primero de ellos, el sector 48, posee un uso global industrial, con un 20 por ciento de usos terciarios y un 10 por ciento residencial, con una edificabilidad lucrativa de 692.398 metros cuadrados. Por su parte, el sector 49 tiene uso industrial tipo jardín, con un 15 por ciento destinado a terciario y un 25 por ciento a residencial, abarcando una edificabilidad lucrativa de 725.263 metros cuadrados. En conjunto el uso residencial lucrativo posibilita la construcción de 3.200 viviendas, la mitad de ellas de protección oficial. BOPVA-A-2012-05484, nº 223 
que, con una ocupación cercana al cien por cien, ya ha ejecutado una inversión público-privada superior a 55,4 millones y cuenta con más de 50 empresas implantadas y una plantilla cercana a los 350 trabajadores.

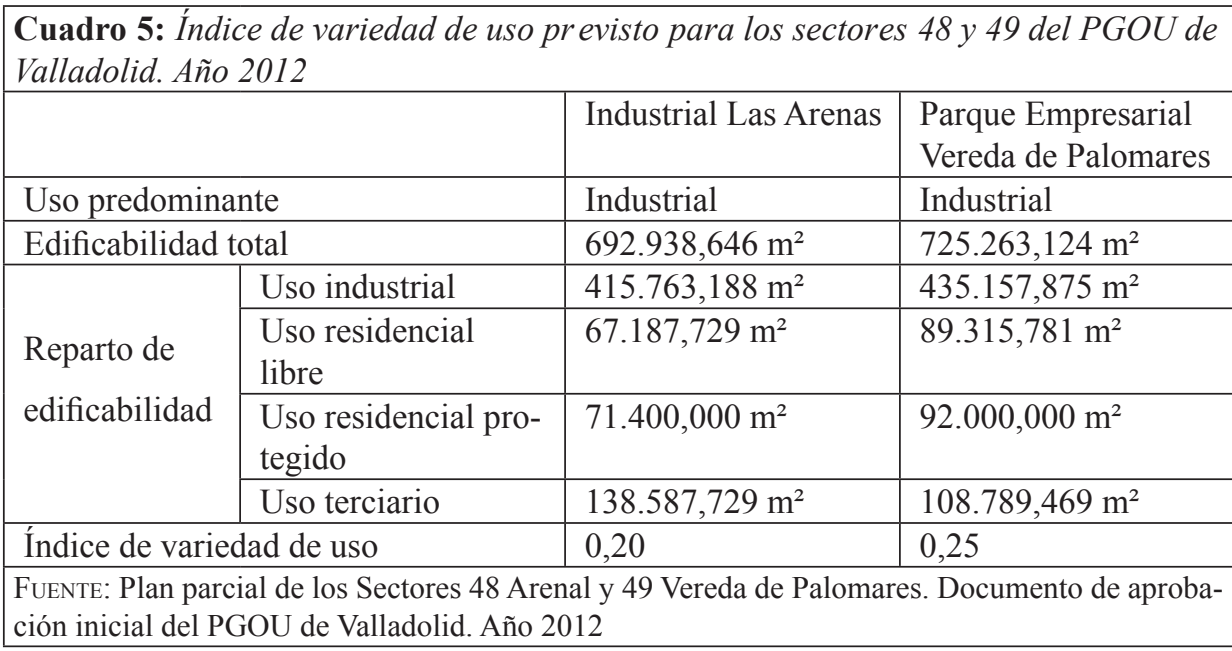

Los problemas que tendrá que afrontar este nuevo espacio industrial y logístico son diversos, siendo quizá los más importantes la falta de definición de las conexiones con la Va-30 o Ronda Exterior y con el by-pass ferroviario, la integración real de un barrio de origen irregular y crecimiento espontáneo como Camino de Palomares y la notable cantidad de viviendas previstas, superior a 3.000, que será muy complicado edificar y ocupar -vender- a la vista de la elevada cantidad de viviendas vacías y suelo residencial calificado ya existente, singularmente en el espacio entre rondas (Va-20 y Va-30) de la ciudad de Valladolid. Se trata por otra parte de un espacio extenso, pero de crecimiento finito, al estar delimitado por dos grandes barreras: el trazado del ferrocarril Madrid Irún, y el nuevo trazado del by-pass de mercancías y el trazado y espacio libre protector del canal del suelo al este y sur. 
Figura 6: La gran alternativa industrial y logística municipal: Polígono Nicas (fotos 6.1 y 6.2) y Vereda de Palomares-Arenal (fotos 6.3 y 6.4)
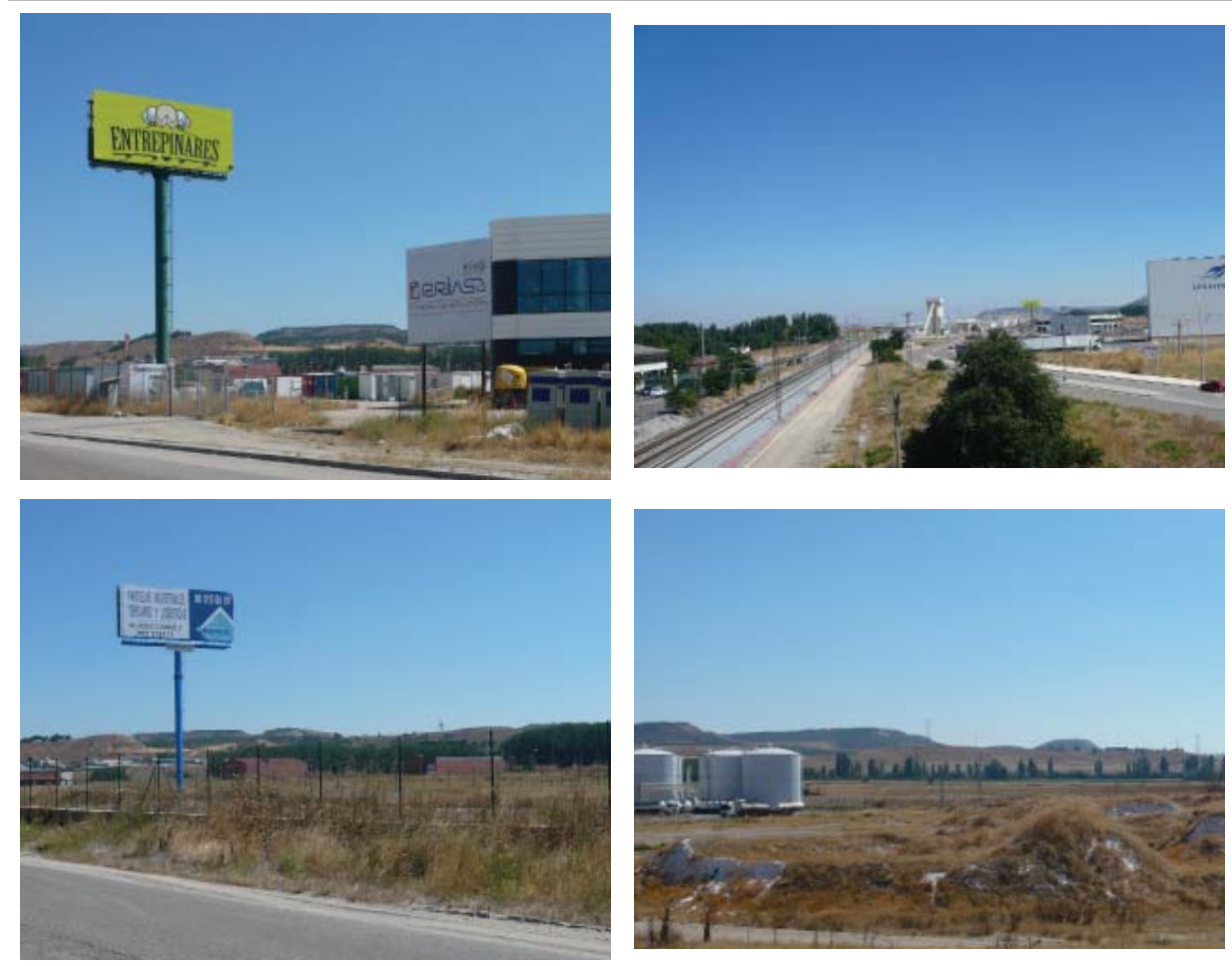

FUENTE: el autor

\section{CONCLUSIONES}

Como en otras ciudades españolas, desde finales del siglo pasado se han vendido diseñando y ocupando nuevas áreas de actividad, vinculadas no como en el pasado a la industria que podemos denominar clásica, orientada en muchos casos al mercado local, sino a atender las necesidades que los cambios en los hábitos de compra-consumo y el incremento de la movilidad demandaban. Por razones obvias, estas áreas ocuparon una posición excéntrica en cada término municipal y resultaron extremadamente eficaces al objeto de reducir el tránsito y aparcamiento de vehículos pesados por el viario local, pero en no pocos casos se han acabado por colmatar, obligando a la búsqueda de espacio perimetral- si lo hubiere- para prolongar algunos años el grado de operatividad que tenían en origen; pero cuando esto no es posible o cuando se ha agotado también el men- 
cionado recurso, una muy buena práctica urbana se acaba por convertir en un problema, que solo se puede solucionar mediante el diseño de nuevas áreas logísticas alternativas a aquellas que han agotado su ciclo de vida útil.

A pesar de los problemas relacionados con su reducido tamaño, así como con las compleja conexión con la A-62 y la Ronda Interior y pese a apoyarse en un único modo, la carretera, la ubicación del Centro Integrado de Mercancías de Valladolid resultó en origen muy adecuada ya que su emplazamiento posee un alto valor estratégico, contemplada la actividad económica local e incluso provincial en su conjunto, dado que por su posición puede proporcionar servicios de transporte y logísticos a la Unidad Alimentaria de Valladolid -MERCAOLID- al igual que a la actividad generada en los grandes polígonos emplazados en torno a la ronda interior este y sur de Valladolid -San Cristóbal, Carrascal, Pinar de Jalón, Mimbreras, Argales etc.- y al cercano polígono industrial Canal de Castilla, ubicado en el municipio de Cigales, una vez concluyan las obras de urbanización del mismo; pero su operatividad será siempre limitada, tanto por sus dimensiones como y sobre todo por la imposibilidad para crecer, al estar emplazado entre en río Pisuerga y los nuevos desarrollos residenciales del barrio de la Victoria; una limitación estructural que se acentúa si tenemos en cuenta la falta de conexión directa con la infraestructura ferroviaria actual y con la que está en construcción en el Sector 53 -Páramo de San Isidro-, es decir, la nueva estación de mercancías y el área logística de Renfe a ella asociada.

Como se ha demostrado, se trata por lo tanto de un área agotada y por ello sometida a cambios ya intuidos en la escala temporal de las decisiones estratégicas sobre la ciudad, que comportará el traslado de uno de los grandes equipamientos -el mercado central o el centro integrado de mercancías-, para permitir el desarrollo del que permanezca en el sector; aunque con ello se perderán las sinergias que ahora se derivan de la proximidad de las mismas. Y es que, no debemos olvidar que los efectos urbanísticos y socioeconómicos de determinadas políticas territoriales no son inmediatos; se advertirán en las próximas generaciones; y cuando se valoren, habrá que volver a reflexionar, probablemente, sobre el verdadero significado de la ordenación de un territorio finito y descoordinado en el que, la competencia por su control entre cercanos, reduce su atractivo y limita considerablemente la capacidad para competir de la economía local y provincial en su conjunto. 


\section{BIBLIOGRAFÍA}

Alvarez Folgueras, C. y Pardo Fanjul, A. (2008): “El transporte de mercancías por carretera en Castilla y León," Pecvnia, 2008; 53-73

Calderón Calderón B., Pascual Ruiz-Valdepeñas, H., Pastor Antolin, L. (2005): "Oportunidad y problemática de las infraestructuras logísticas en ámbitos urbanos: el caso de Valladolid.”; Ciudad y territorio-Estudios Territoriales XXXVII (143); 145-168.

Calderón Calderón, B., Pascual Ruiz-Valdepeañas, H., Pastor Antolín, L., Sainz GueRRA, J. L., García Cuesta, J. L. (2003): Plataforma Logística multimodal. Universidad de Valladolid. Departamento de Geografía. 191 pp.

Calderón Calderón, B. y Pascual Ruiz-Valdepeñas, H. (2007): Estructuras territoriales al servicio de la actividad económica: sistema de estaciones, centros logísticos y centros de servicio al transporte. Universidad de Valladolid. Dpto. de Geografía. 80 p.

Calderón Calderón, B. y Pascual Ruiz-Valdepeñas, H. (2009): “Infraestructuras de soporte en los procesos de innovación regional: nuevos espacios productivos en Castilla y León.” Boletín de la Asociación de Geógrafos Españoles, (49); 237-254.

CeCale (2007): Estudio sectorial sobre la situación y perspectivas en el transporte de mercancías por carretera de Castilla y León. Perspectiva del modelo CyLOG. Valladolid 2007, $176 \mathrm{p}$.

del Rio la Fuente, I. y Rodriguez Moya, J. (2012): "Nuevos espacios para las actividades logísticas. Una revisión crítica para el caso de la Comunidad de Madrid”. Ería, 2012, nº 89, 275-290.

España. Ministerio de Fomento (2005): PEIT: Plan estratégico de infraestructuras y transporte 2005- 2020. Madrid: Centro de Publicaciones, $182 \mathrm{p}$.

Fernandez Noguerol, S. (2013): La implantación de la Zona de Actividades Logísticas de Asturias y su repercusión territorial" Ería, 2013, no 90, 55-74.

Gutierrez Puebla, J. y Garcia Palomares, J.c.(2010): "Procesos de descentralización de las actividades en el área metropolitana de Madrid”.En Feria, J.M. y Albertos Puebla, J.M.: La ciudad metropolitana en España. Procesos urbanos en los inicios del siglo XXI. Civitas.

López González, A., Benito del Pozo, P. (2012): “El modelo CylOG: la ordenación territorial de la actividad logística en Castilla y León”. XXXVIII Reunión de Estudios Regionales.

Ministerio DE Fomento (2010): Observatorio del transporte de mercancías por carretera. Secretaría de Estado de transportes. Dirección General de Transporte Terrestre. Madrid.

Ministerio de Fomento (2013): Estrategia logística de España . Madrid, 138 p. https:// www.fomento.gob.es 
Morales GiL, A. (2010): “Las superficies logísticas y la organización espacial de redes de transporte de mercancías en España." Papeles de Geografía. 2010, 51-52; 211-222

Oliveras Sitjar, B. (2009): “Organización del mantenimiento de un área logística. La ZAL del puerto de Barcelona". Mantenimiento: ingeniería industrial y edificios. Barcelona, $\mathrm{n}^{\mathrm{o}}$ 26, 23-31

Pascual Ruz Valdepeñas, H. (2012): "El significado de la industria y de las nuevas infraestructuras en la estructuración territorial” En DELGADO URRECHO, J. $\mathrm{M}^{\mathrm{a}}$ : Población y poblamiento en Castilla y León . Ed. C.E.S. Castilla y León, Valladolid 2012, 638-737

Pastor Antolin, L., Pascual Ruiz-Valdepeñas, H. (1994): Conocer el barrio de Los Pajarillos. Una compleja periferia obrera de la ciudad de Valladolid. Ayuntamiento de Valladolid, 1994.

Ponce Herrero, G. (2008): "La cualificación terciaria del suelo industrial en Alicante: hacia el diseño de una plataforma logística" Investigaciones Geográficas, $\mathrm{n}^{\mathrm{o}}$ 47, 2008, 27-48

Rivas SANZ, J.L. (2008): “Accesibilidad, logística y ordenación del territorio en Castilla y León”, Boletín Económico de Castilla y León, n 16, 47-48.

Rodríguez GutiérRez, F. (2010):'Distribución especial y características de los principales elementos del sistema logístico de Asturias”. Cuadernos Geográficos vol. 47, 379-402

Robuste Anton, F. (1999): “Logística de la distribución urbana de mercancías”. Actas del I Congreso Internacional de Tráfico Urbano, pág. 141-174. Madrid, 14-16 de abril de 1999.

RuilobA, A. (2008): "La Junta de Castilla y León finaliza la Autovía Valladolid-Segovia" En: Rutas: Rev. de la Asociación Técnica de Carreteras, №. 128, 59-64.

http://www.cylog.es/

http://www.mercaolid.es/ 


\begin{tabular}{|c|c|c|}
\hline \multicolumn{3}{|c|}{ ANEXO 1: Principales áreas industriales de Valladolid y su entorno. Año 2011} \\
\hline Denominación & Municipio & Extensión -m²- \\
\hline \multicolumn{3}{|c|}{ Autovía A 62 Entorno de Valladolid } \\
\hline P.I. El Arenal & Santovenia de Pisuerga & 63.080 \\
\hline P.I. El Esparragal & Santovenia de Pisuerga & 100.000 \\
\hline P.I. Las Panaderas & Santovenia de Pisuerga & 20.000 \\
\hline Z.I. Nicas & Santovenia de Pisuerga & 115.792 \\
\hline P.I. Sector IV & Cabezón & 374.000 \\
\hline P.I Sector V & Cabezón & 26.336 \\
\hline Área de Actividades Canal de Castilla & Cigales & 3.515 .274 \\
\hline \multicolumn{3}{|c|}{ Autovía A 11. Entorno de Valladolid } \\
\hline P.I. La Mora & Cisterniga & 1.234 .509 \\
\hline P.I. Tuduero & Tudela de Duero & 759.118 \\
\hline \multicolumn{3}{|c|}{ Nacional N 6. Carretera de Madrid } \\
\hline P.Tecnológico de Boecillo, fase I & Boecillo & 450.000 \\
\hline P.Tecnológico de Boecillo, fase II & Boecillo & 83.000 \\
\hline P.Tecnológico de Boecillo, fase III & Boecillo & 573.600 \\
\hline \begin{tabular}{|l|} 
P.I. Las Lobas \\
\end{tabular} & Laguna de Duero & 251.928 \\
\hline P.I. Los Alamares & Laguna de Duero & 539.495 \\
\hline Autovía & torno de Valladolid & \\
\hline
\end{tabular}

\begin{tabular}{|l|l|r|}
\hline P.I. Sector 16 & $\begin{array}{l}\text { Arroyo de la Enco- } \\
\text { mienda }\end{array}$ & 305.715 \\
\hline P.I. Sector 8 & $\begin{array}{l}\text { Arroyo de la Enco- } \\
\text { mienda }\end{array}$ & 10.869 \\
\hline P.I. Simancas & Simancas & 718.770 \\
\hline $\begin{array}{l}\text { Parque Logístico Empresarial de } \\
\text { Tordesillas }\end{array}$ & Tordesillas & 2.100 .570 \\
\hline P.I. La Vega & Tordesillas & 257.250 \\
\hline P.I. Valdegalindo & Tordesillas & 301.566 \\
\hline \multicolumn{2}{|l}{} & 138.274 \\
\hline Autovía A 60. Entorno de Valladolid & \multicolumn{2}{|l|}{} \\
\hline P.I. San Cosme I & Villanubla & 218.060 \\
\hline P.I. San Cosme II & Villanubla & 358.124 \\
\hline P.I. San Cosme III & Villanubla & 150.000 \\
\hline P.I. San Cosme IV & Villanubla & 230.000 \\
\hline P.I. Fuensaldaña & Fuensaldaña & 50.000 \\
\hline P.I. Fuensaldaña II (El Molar) & Fuensaldaña & \\
\hline
\end{tabular}


AREAS INDUSTRIALES EN VALLADOLID

\begin{tabular}{|l|l|r|}
\hline Denominación & Municipio & Extensión $-\mathrm{m}^{2}-$ \\
\hline Parque Empresarial Las Cerámicas & Valladolid & 148.308 \\
\hline P.I. Arcas Reales & Valladolid & 3.350 \\
\hline P.I. Argales & Valladolid & 817.455 \\
\hline P.I. Carrascal & Valladolid & 68.709 \\
\hline P.I. Casasola & Valladolid & 7.184 \\
\hline P.I. Cerro de San Cristóbal & Valladolid & 2.650 .000 \\
\hline P.I. El Berrocal & Valladolid & 123.000 \\
\hline P.I. Las Arenas & Valladolid & 1.280 .000 \\
\hline P.I. Las Mimbreras & Valladolid & 7.000 \\
\hline P.I. Las Raposas & Valladolid & 320.000 \\
\hline P.I. Las Raposas II & Valladolid & 3.588 \\
\hline P.I. Los Santos & Valladolid & 71.868 \\
\hline P.I. Industrial Jalón y Campo de tiro & Valladolid & 700.000 \\
\hline Nuevo complejo ferroviario & Valladolid & \\
\hline Fuente: http://www.invertirencastillayleon.jcyl.es & \\
\hline
\end{tabular}




\begin{tabular}{|c|c|c|c|c|}
\hline \multicolumn{5}{|c|}{$\begin{array}{l}\text { ANEXO 2: Toneladas transportadas según tipo de desplazamiento por Comuni- } \\
\text { dades Autónomas. Año } 2012\end{array}$} \\
\hline \multirow[b]{2}{*}{ Comunidad Autónoma } & \multirow{2}{*}{$\begin{array}{l}\text { Transporte } \\
\text { intrarregional. } \\
\text { Miles de tn. } \\
\text { Total }\end{array}$} & \multicolumn{2}{|c|}{$\begin{array}{l}\text { Transporte interregional. } \\
\text { Miles de tn. }\end{array}$} & \multirow{2}{*}{$\begin{array}{l}\text { Parque de } \\
\text { vehículos } \\
\text { pesados } \\
\left(\mathrm{n}^{\circ}\right)\end{array}$} \\
\hline & & $\begin{array}{l}\text { Recibido de } \\
\text { otras CC.AA. }\end{array}$ & $\begin{array}{l}\text { Expedido a } \\
\text { otras } \\
\text { CC.AA }\end{array}$ & \\
\hline TOTAL & 894.025 & 279.960 & 279.960 & 320.809 \\
\hline Andalucía & 143.867 & 23.500 & 21.137 & 48.499 \\
\hline Aragón & 33.518 & 20.363 & 21.444 & 12.472 \\
\hline Asturias, Principado de & 31.570 & 8.026 & 9.143 & 7.601 \\
\hline Balears, Illes & 16.088 & 1.439 & 360 & 5.345 \\
\hline Canarias & 30.345 & & & 13.884 \\
\hline Cantabria & 10.946 & 6.781 & 8.277 & 5.690 \\
\hline Castilla-La Mancha & 41.482 & 27.374 & 32.361 & 23.741 \\
\hline Castilla y León & 72.330 & 24.830 & 29.485 & 26.716 \\
\hline Cataluña & 162.195 & 27.981 & 30.362 & 44.393 \\
\hline Comunidad Valenciana & 103.139 & 38.285 & 30.526 & 35.681 \\
\hline Extremadura & 25.278 & 8.101 & 5.578 & 8.158 \\
\hline Galicia & 87.308 & 10.541 & 11.067 & 23.053 \\
\hline Madrid, Comunidad de & 42.187 & 33.325 & 28.197 & 26.240 \\
\hline Murcia, Región de & 29.224 & 11.539 & 17.097 & 16.339 \\
\hline Navarra, C. Foral de & 16.917 & 10.323 & 10.875 & 5.955 \\
\hline País Vasco & 42.076 & 22.301 & 19.305 & 13.692 \\
\hline Rioja, La & 4.486 & 5.090 & 4.729 & 3.077 \\
\hline Ceuta y Melilla & 1.069 & 160 & 18 & 273 \\
\hline
\end{tabular}




\begin{tabular}{|c|c|}
\hline \multicolumn{2}{|c|}{$\begin{array}{c}\text { ANEXO 3: Dos décadas de desarrollo normativo del centro integrado de mercan- } \\
\text { cías de Valladolid }\end{array}$} \\
\hline Fecha & Normativa-instrumento de planeamiento \\
\hline 04.07 .1990 & $\begin{array}{l}\text { Aprobación por el pleno del Ayuntamiento de Valladolid del convenio } \\
\text { de colaboración con la Junta de Castilla y León para la construcción } \\
\text { de un Área de Transporte. }\end{array}$ \\
\hline 23.12 .1991 & $\begin{array}{l}\text { Aprobación inicial por el Pleno del Ayuntamiento del establecimiento } \\
\text { de reserva de terrenos para su adjudicación con destino al patrimonio } \\
\text { municipal de suelo. }\end{array}$ \\
\hline 08.07 .1992 & $\begin{array}{l}\text { Aprobación definitiva por el Pleno del Ayuntamiento del estableci- } \\
\text { miento de reserva de terrenos para su adjudicación con destino al pa- } \\
\text { trimonio municipal de suelo. }\end{array}$ \\
\hline 29.03 .1993 & $\begin{array}{l}\text { Acuerdo del plano de formulación del Programa de Actuación urbanís- } \\
\text { tica para el desarrollo del sector 15, Industrial Cabildo Sur. }\end{array}$ \\
\hline 15.07 .1993 & $\begin{array}{l}\text { Aprobación inicial por el Pleno del P.A.U. y Plan Parcial del sector } n^{\circ} \\
15\end{array}$ \\
\hline 10.04 .1994 & $\begin{array}{l}\text { Aprobación provisional por el Pleno del P.A.U. y Plan Parcial del sec- } \\
\text { tor } n^{\circ} 15\end{array}$ \\
\hline 10.11 .1994 & $\begin{array}{l}\text { Aprobación inicial por el pleno del proyecto de urbanización del sec- } \\
\text { tor } 15\end{array}$ \\
\hline 17.05 .1995 & $\begin{array}{l}\text { Orden de la Consejería de Medio Ambiente y Ordenación del Territo- } \\
\text { rio por la que se aprueba definitivamente el P.A.U. del sector } 15\end{array}$ \\
\hline 17.05 .1995 & $\begin{array}{l}\text { Orden dela consejería de Medio Ambiente y Ordenación del Territorio } \\
\text { por la que se aprueba definitivamente la modificación del PGOUVa en } \\
\text { relación con la descatalogación del edificio sito en el } C^{o} \text { del Cabildo } n^{\circ} \\
25 \text {. }\end{array}$ \\
\hline 27.07 .1995 & $\begin{array}{l}\text { Aprobación definitiva del Proyecto del Plan Parcial del sector } n^{\circ} 15, \\
\text { Industrial Cabildo Sur }\end{array}$ \\
\hline 27.07 .1995 & $\begin{array}{l}\text { Aprobación definitiva del Proyecto de Urbanización del sector } \mathrm{n}^{\mathrm{o}} 15, \\
\text { Industrial Cabildo Sur }\end{array}$ \\
\hline 08.01 .1997 & Aprobación definitiva. Proyecto de normalización de fincas. \\
\hline 8.10 .1997 & $\begin{array}{l}\text { Adjudicación a Centrolid del Concurso para la Construcción y explo- } \\
\text { tación de la terminal de mercancías de Valladolid }\end{array}$ \\
\hline 09.12 .1997 & Aprobación inicial de la modificación del Plan parcial del sector $\mathrm{n}^{\mathrm{o}} 15$ \\
\hline 07.04 .1998 & Aprobación inicial de la modificación del Proyecto de Urbanización \\
\hline 10.09 .1998 & $\begin{array}{l}\text { Aprobación definitiva de la modificación del proyecto de urbanización } \\
\text { del sector } 15\end{array}$ \\
\hline
\end{tabular}




\begin{tabular}{|l|l|}
\hline 28.09.1998 & $\begin{array}{l}\text { Aprobación definitiva de la Modificación del proyecto de urbanización } \\
\text { del sector 15 }\end{array}$ \\
\hline 04.07.2001 & $\begin{array}{l}\text { Aprobación definitiva de la modificación n }{ }^{\circ} \text { 2 del plan Parcial del sec- } \\
\text { tor n }^{\circ} 15\end{array}$ \\
\hline 14.12.2007 & $\begin{array}{l}\text { Aprobación inicial del estudio de detalle para la ejecución de una pa- } \\
\text { sarela de unión entre edificios administrativos en la parcela 17.1 del } \\
\text { sector 6 (antes 15) industrial Cabildo Sur. }\end{array}$ \\
\hline 06.05.2008 & $\begin{array}{l}\text { Aprobación definitiva del estudio de detalle para la ejecución de una } \\
\text { pasarela de unión entre edificios administrativos en la parcela 17.1 del } \\
\text { sector 6 (antes 15) industrial Cabildo Sur. }\end{array}$ \\
\hline 28.10.2011 & $\begin{array}{l}\text { Aprobación definitiva. Modificación del proyecto de normalización de } \\
\text { fincas del sector 15 "Industrial Cabildo Sur", manzanas 3, 4, 5, 6 }\end{array}$ \\
\hline FuENTE: Elaboración propia
\end{tabular}

